\title{
Host factors and HIV-1 replication: clinical evidence and potential therapeutic approaches
}

\author{
Mariana Santa-Marta ${ }^{1,2}$ *, Paula Matos de Brito ${ }^{1,2}$, Ana Godinho-Santos ${ }^{1,2}$ and Joao Goncalves ${ }^{1,2 *}$ \\ 1 URIA-Centro de Patogénese Molecular, Faculdade de Farmácia, Universidade de Lisboa, Lisboa, Portugal \\ 2 Instituto de Medicina Molecular, Faculdade de Medicina da Universidade de Lisboa, Lisboa, Portugal
}

\author{
Edited by: \\ Nitin Kumar Saksena, Westmead \\ Hospital, Westmead Milennium \\ Institute, Australia

\section{Reviewed by:} \\ Clive Maurice Gray, University of \\ Cape Town, South Africa \\ Nitin Kumar Saksena, Westmead \\ Hospital, Westmead Milennium \\ Institute, Australia \\ *Correspondence: \\ Mariana Santa-Marta and Joao \\ Goncalves, URIA - Centro de \\ Patogénese Molecular, Faculdade de \\ Farmácia, Universidade de Lisboa, Av. \\ Prof. Gama Pinto, 1649-003 Lisboa, \\ Portugal \\ e-mail: msanta_marta@ff.ul.pt; \\ joao.goncalves@ff.ul.pt
}

HIV and human defense mechanisms have co-evolved to counteract each other. In the process of infection, HIV takes advantage of cellular machinery and blocks the action of the host restriction factors (RF). A small subset of HIV+ individuals control HIV infection and progression to AIDS in the absence of treatment. These individuals known as long-term non-progressors (LNTPs) exhibit genetic and immunological characteristics that confer upon them an efficient resistance to infection and/or disease progression. The identification of some of these host factors led to the development of therapeutic approaches that attempted to mimic the natural control of HIV infection. Some of these approaches are currently being tested in clinical trials. While there are many genes which carry mutations and polymorphisms associated with non-progression, this review will be specifically focused on HIV host RF including both the main chemokine receptors and chemokines as well as intracellular RF including, APOBEC, TRIM, tetherin, and SAMHD1. The understanding of molecular profiles and mechanisms present in LTNPs should provide new insights to control HIV infection and contribute to the development of novel therapies against AIDS.

Keywords: human immunodeficiency virus, nonprogressors, APOBEC, TRIM, tetherin, SAMHD1, chemokine receptors, chemokine

\section{INTRODUCTION}

Both pathogens and host have an inherent variability that plays a critical role in the consequences of the infection process. When infected by a specific pathogen, some individuals show no sign of HIV infection or react with moderate manifestations, while others rapidly succumb to the disease. Likewise, heterogeneity in the predisposition to HIV-1 infection has been reported in numerous cohort studies. Approximately $5 \%$ of infected patients seem to be unaffected by HIV-1 infection regardless of repeated exposure to the virus by unsafe sexual practices or blood transfusion. Subsequent studies showed the presence of fully replication-competent virus in these long-term non-progressors (LTNPs), which changed the attention to the host.

Understanding what makes non-progressors "immune" to HIV infection is a challenge, as the cohort is not homogeneous. A particular phenotype is the result of specific combinations of factors including the virus strain, each individual immune response and genetic background. Individual variability results from the exchange of genes during meiosis and various mutational events. However, population variability results from natural selection, migration, and bottleneck effects, phenomena that can be analyzed to obtain relevant information about a specific research subject. The study of HIV non-progressors is therefore critical for the understanding of the underlying mechanisms of HIV control that results in low viral replication and/or slow disease progression ( $>15$ years to AIDS) in the absence of therapy (1).

The initial studies on these patients were based on DNA profiling and single nucleotide polymorphism (SNP) genotyping studies that only covered about $0.1 \%$ of the entire genome. Although limited in terms of information, they led to the identification of important population-specific polymorphisms that influence HIV-1 infection and progression to disease. One of the most studied genetic variations influencing HIV-1 infection and progression is the $\Delta 32$ mutation in the CCR5 gene (2), and SNPs in various chemokine receptors or HLA class I and class II alleles $(3,4)$. More recently, the use of genome-wide association studies (GWAS) and meta-analysis studies highlighted relevant information on the genetic backgrounds of progressors and non-progressors at a genome-wide level (5).

Non-progressor phenotypes can be explained, at least in part, in terms of host factors that limit HIV infection and disease progression. Here, we review the latest advances in the identification of host factors that determine the vulnerability of cells to viral infection, and discuss their current therapeutic usage and potential. We focus on those factors which restrict the entrance of HIV into the host cell and its later release, such as chemokine co-receptors and their ligands, SAMHD, TRIM, APOBEC, and tetherin.

\section{ROLE OF CHEMOKINE RECEPTORS AND THEIR GENETIC VARIABILITY IN HIV INFECTION}

Several chemokine receptors have been described as mediators of HIV-1 entry. However, CCR5 and CXCR4 are considered the clinically relevant receptors in vivo [reviewed in Alkhatib (6)]. CCR5 and CXCR4 are two structurally related chemokine receptors that belong to different classes (C-C and CXC, respectively) of the superfamily of $\mathrm{G}$ protein-coupled receptors (GPCRs). GPCRs are transmembrane proteins characterized by seven transmembrane $\alpha$-helices (TM1-TM7) which are connected by six loops 
(ECL1-ECL3 and ICL1-ICL3) (Figure 1). CCR5 was first characterized as a receptor for MIP- $1 \alpha$, MIP-1 $\beta$, and RANTES (7) and later described as a co-receptor for HIV-1 (8). This receptor is highly expressed at the surface of B cells, monocytes, macrophages, dendritic cells (DC), microglial cells, and memory $\mathrm{T}$ cells, but rarely in näive CD4+ T cells $(9,10)$. CXCR4 is also a co-receptor for HIV-1 (11), and its natural ligand is SDF-1/CXCL12. This receptor is expressed on the surface of näive CD4+ T cells, peripheral blood B cells, monocytes, but not on mature macrophages $(9,10)$. Viruses capable of exploiting CCR5 (R5-tropic) are predominant during the asymptomatic phase of HIV infection, whereas viruses found in late-stage disease use preferentially CXCR4 as their coreceptor (being X4- and R5X4-tropic if they can use both) (12, 13). CXCR4 has an essential role during development (14), which might explain the lack of non-coding variants for CXCR4. The only non-silent CXCR4 polymorphism identified in several HIV-1 infected individuals, the CXCR4 T278C change, was not yet proven to be associated with progression to AIDS (15). However, there are polymorphisms in CCR5 and other chemokine co-receptors that play a key role in natural protection against HIV transmission and progression (16).

The $\Delta 32$ mutation in the CCR5 gene (CCR5 $\Delta 32)$ is probably the most studied genetic variation of a host protein in relation to HIV-1 infection and progression. Due to a $32 \mathrm{bp}$ deletion in the gene sequence, a premature stop codon is introduced, leading to the production of a truncated CCR 5 protein. This polymorphism is mostly present in European populations, with higher prevalence in Northern Europe, and is virtually absent in African, Asian, and American Indian populations.

Individuals homozygous for the CCR5 $\Delta 32$ polymorphism $(1 \%$ in Europe) do not express CCR5 at the cell-surface and are therefore naturally resistant to the infection by HIV R5-tropic strains, but not by HIV-1 strains that can use a different co-receptor. Indeed, the rare cases of seropositive homozygotic individuals reported so far were infected with CXCR4 HIV strains alone or in combination with a CCR5 tropism (2, 17-25). Heterozygotic individuals are not protected against HIV-1 infection but, in most cohort studies, they have been found to have lower viral loads, slower decrease in the CD4+ T cell count and slower progression to AIDS by an additional 2-3 years when compared to CCR5-wildtype individuals (26-29). The discrepancies found in other studies that failed to correlate CCR $5 \Delta 32$ heterozygocity with delayed disease progression could be due to small sample size, infection by dual-tropic HIV-1 strains or individual differences at the level of functional expression of CCR5 receptors, which also depends on epigenetics and trans-acting factors, for instance (30-32). Despite these contradictory results, meta-analyses of published cohorts associate the CCR5 $\Delta 32$ allele with lower HIV-1 RNA, decreased risk of progression to AIDS and lower mortality rate in adults (33, 34). GWAS performed on individuals from Euro-CHAVI, MACS cohort, and the International HIV controllers study 2010 further confirmed the protective effect of the CCR5 $\Delta 32$ allele in viral load control and progression to $\operatorname{AIDS}(35,36)$. Another truncated form of CCR5, the CCR5-m303A, also conferred resistance to $\mathrm{HIV}-1$ infection in vitro. CCR5-m303A is a $\mathrm{T} \rightarrow \mathrm{A}$ transition at nucleotide 303 which also introduces a premature stop codon resulting in a CCR5 protein that no longer facilitates cell fusion
(37). This further supports the putative relevance of CCR5 as a target for HIV therapies.

Several SNPs in the CCR5 cis-regulatory region, grouped in at least 10 haplotypes (CCR5-P1 to P10), have been described as changing the course of AIDS. Studying the effects of specific polymorphisms has been challenging due to linkage imbalance across the locus, particularly with CCR2 (Figure 1). Of particular interest is the CCR5-59029 A/G polymorphism, which has been associated with different rates of AIDS progression. HIV-1-infected CCR559029 G/G homozygotic individuals progressed slower to AIDS
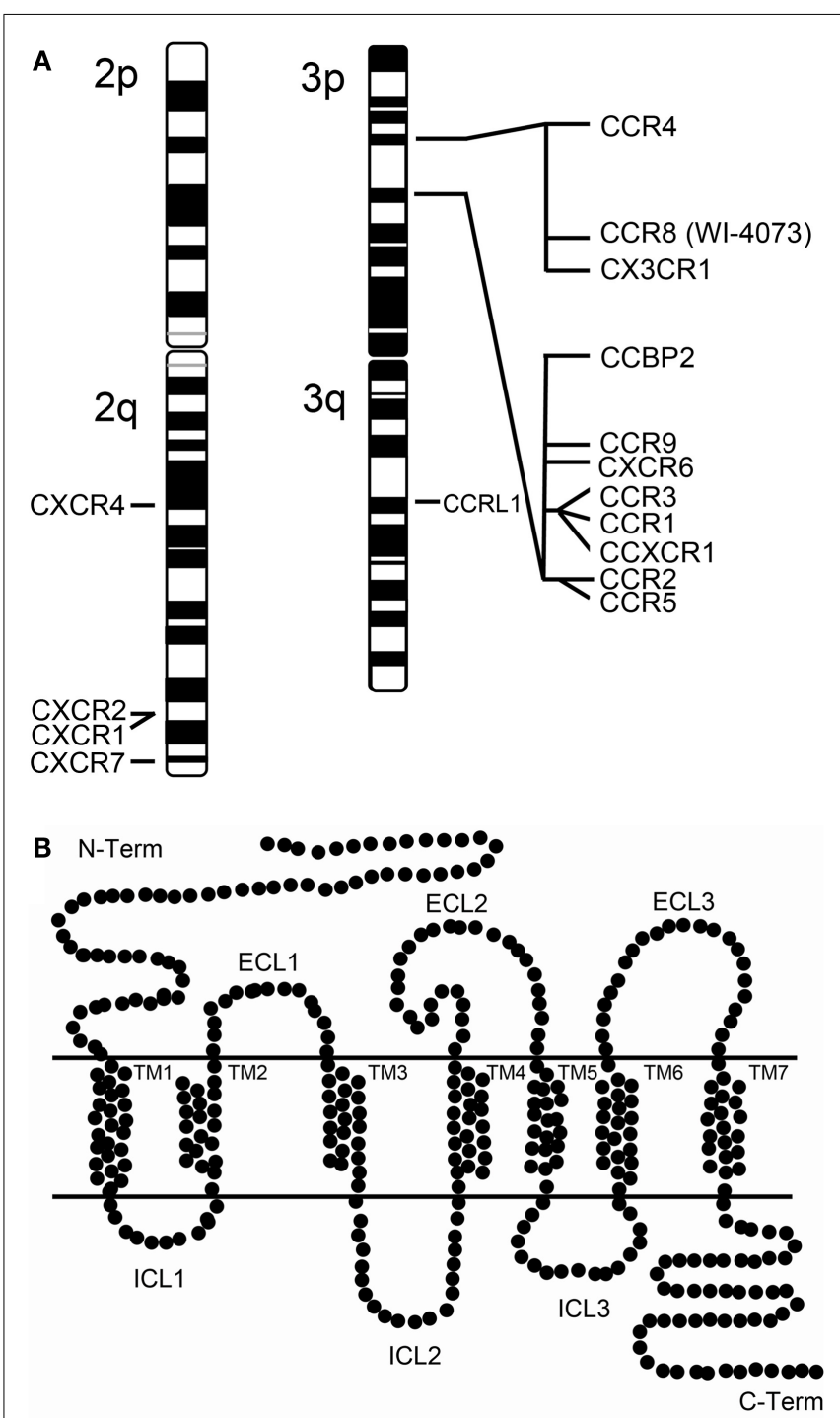

FIGURE 1 | Human chemokine receptors. (A) Chromosomal map of the human chemokine receptor genes at chromosome 2 and 3 . Of notice that the chromosome $3 p$ harbors two chemokine receptor clusters.

(B) Schematic representation of a chemokine receptor. Chemokine receptors belong to the superfamily of $\mathrm{G}$ protein-coupled receptors (GPCRs) which are transmembranar proteins characterized by possessing an extracellular $\mathrm{N}$-terminus and an intracellular $\mathrm{C}$-terminus structure and seven transmembrane $\alpha$-helices (TM1-TM7) connected extracellularly and intracellularly by six loops (ECL1-ECL3 and ICL1-ICL3). 
and/or death than HIV-1-infected CCR5-59029 A/A homozygotic individuals (38-40). The frequency of the 59029G allele is significantly increased in exposed seronegative Caucasian men compared to healthy controls (41). G/G, A/G, and A/A promoter genotypes correlated with low, medium, and high viral propagation and CCR5 receptor density, respectively, in in vitro studies (42). Promoters containing the $59029 \mathrm{G}$ allele showed reduced activity (45\%) versus promoters containing the 59029A allele (40). These data strongly suggest that the mechanism underlying the protective effect of the $59029 \mathrm{G}$ allele is a lower expression of CCR5. Moreover, the combination of haplotypes CCR5 $\Delta 32 /$ CCR5-59029A (in complete linkage disequilibrium) and CCR5wt/CCR5-59029G had a cumulative negative effect on CCR5 expression that conferred an advantage in resisting sexual HIV-1 transmission (41). The CCR5-59353 C allele has been associated with accelerated disease progression and its frequency has been reported to be higher in AIDS patients than in LTNPs $(38,43,44)$. On the other hand, Easterbrook et al. (45) observed a correlation between the CCR5-59353 CC genotype and a delay on $\sim 40 \%$ of the subjects in progression to a CD4+ cell count lower than 200; and a higher prevalence of the CCR5-59353C promoter polymorphism among non-progressors compared with those with progressing disease (45). However, they also found that the CCR5-59353 CC genotype was not associated with a delay in the CDC stage IV disease.

The CCR2 chemokine receptor (also termed CKR2; CCR2A; CCR2B; CD192; MCP-1-R; CC-CKR-2) is an alternative coreceptor for HIV-1 infection that is only used by a few strains. CCR2 constitutively forms homodimers and heterodimers with both CCR5 and CXCR4 (46-50). This gene is located in the chemokine receptor gene cluster region, and it codes for two alternatively spliced transcript variants (CCR2a and CCR2b) (Figure 1). The CCR2 V64I (rs1799864) polymorphism identified with similar frequencies (10-20\%) in all ethnicities, has an alteration within the first transmembrane domain of the receptor. This polymorphism does not affect CCR2 co-receptor levels of expression and activity. It is associated with reduced levels of CXCR4 in PBMCs from healthy donors (51); and with a delayed progression to AIDS or death (52-56). However, it does not confer any protection against HIV-1 transmission (57), as exposed uninfected individuals present the same CCR2-64I genotype frequency as HIV-infected individuals and healthy controls in an Indian cohort (58) and in exposed uninfected individuals from both Thai and Puwmani sex worker cohorts (59). The V64I polymorphism is in linkage disequilibrium with point mutations (59353 T/C; 59402 $\mathrm{G} / \mathrm{A}$, and $59653 \mathrm{C} / \mathrm{T}$ ) located in the CCR5 regulatory region due to their close proximity in the chemokine receptor cluster located in chromosome 3 (Figure 1) (60). These observations suggested that the CCR2 V64I polymorphism might prevent HIV progression due to a side-effect on CCR5 receptor expression. However, no association was found between this SNP and CCR5 downregulation. A post-entry regulatory mechanism such as the one resulting from co-receptor heterodimerization or receptor desensitization, cannot be ruled out. CCR2 V64I polymorphism has been described to interfere with cell-surface location of CCR5 (61) and CXCR4 (51), as well as with the CCR5 to CXCR4 transition $(62,63)$. It can also modulate the heterodimerization of the co-receptors, thus antagonizing HIV infection during the course of the disease $(46,49,50,64)$. Consistent with this second option, the monoclonal antibody CCR2-01 prevents HIV-1 replication by inducing heterooligomerization of CCR2 with CCR5 or CXCR4 viral co-receptors (64). The protective effect conferred by the V64I polymorphism was confirmed in a meta-analysis of individual patient data of European and African descent (34); and, more recently, by a GWAS where a total of 2554 seroconverters and seroprevalent Caucasians were related to their viral load and disease progression (35). These observations led to the development of alternative anti-HIV-1 therapies that target alternative co-receptors like CCR2 (65).

CXCR6 (also termed STRL33/BONZO/TYMSTR) is the main co-receptor for the simian immunodeficiency virus (SIV) and a secondary co-receptor for HIV that mediates the fusion of HIV$1 \mathrm{M}$-tropic and dual-tropic strains to CD4 T+ cells. GWAS of LTNPs of a French Caucasian cohort led to the identification of the CXCR6 rs2234358 polymorphism (66). This was further confirmed in three other cohorts of European descent. This CXCR6 variant alters CXCR6 levels of expression and acts independently from the CCR2-CCR5 loci as individuals carrying the CXCR6 mutation did not present any alteration in their CCR2-CCR5 loci. In addition, its action was not linked to a decrease in viral load, as LTNPs had a similar viral load mean as controls (66). Another CXCR6 variant, the CXCR6-E3K or rs2234355, has been related to an increased survival from Pneumocystis carinii pneumonia (PCP) in African-Americans infected with HIV-1 (67). This polymorphism results in the substitution of an acidic residue by a basic amino acid residue in the third codon of the co-receptor, located extracellularly. This could interfere with the receptor-ligand or receptor-gp120 affinity, or lead to a CXCR6 trafficking problem, decreasing the levels of CXCR6 at the cell-surface (68). However, patients carrying the CXCR6-E3K allele and under highly active anti-retroviral therapy (HAART) show a faster virologic failure (sustained viral load $<200$ copies $/ \mathrm{mL}$ ) revealing a harmful effect under HAART (69).

The CX3CR1 chemokine receptor (also termed CCRL1) is an alternative co-receptor for HIV-1 infection that seems to play an important role in HIV-1-associated dementia, immune cell recruitment, and possibly in infection expansion. The possible role of two non-synonymous SNPs, CX3CR1-V249I (rs3732379), and CX3CR1-T280M (rs3732378), in HIV progression to AIDS remains controversial. Both SNPs were initially associated with a faster disease progression in three HIV-1-infected French cohorts (70): patients with intermediate progression (IMMUNOCO cohort), patients with asymptomatic long-term progression (ALT cohort), and patients with a known date of seroconversion (SEROCO cohort) (71-73). However, in three North American cohorts of HIV-1 seroconverters [D.C. Gay cohort (DCG), the Multicenter AIDS Cohort Study of homosexual men (MACS), and the Multicenter Hemophilia Cohort Study (MHCS)] and in the Genetics of Resistance to Immunodeficiency Virus (GRIV) cohort, which are also representative of Caucasian descent, no association was found between these polymorphisms and disease progression $(74,75)$. On the other hand, the CX3CR1-V249I was found to be more frequent in Spanish HIV-1-infected LTNPs for more than 15 years in a study with a total of 271 Spaniards (LTNPs, progressors, and uninfected controls) (76) and in another study, patients 
carrying CX3CR1-V249I or T280M polymorphisms showed an improved immunologic response to HAART (69). The CX3CR1T280M allele was also associated with higher peripheral CD4+ T cell counts in HIV-infected and healthy subjects, showing that these polymorphisms confer protection in the presence of HAART (54). In summary, the role of CX3CR1 polymorphisms in HIV infection and disease progression remains to be elucidated.

\section{CYTOKINES AND CHEMOKINE VARIANTS}

HIV-1 transmission and progression to AIDS can be influenced by allelic polymorphisms in several chemokine and cytokine genes. Cytokines are small signaling peptides that modulate cell functions by means of matching cell-surface receptors. Chemokines are a group of cytokines especially involved in immunological and inflammatory responses that are ligands to GPCRs and share common structural features.

\section{CCR5 LIGANDS}

CCR5 ligands can be divided in two groups. MIP-1 $\alpha$ (CCL3), MIP$1 \beta$ (CCL4), and RANTES (CCL5) bind efficiently to CCR5 and are full agonists, while MCP-2, MCP-3, and MCP-4 exhibit diverse efficiency and potency in receptor activation (6). Two additional variants, CCL3L1 and CCL4L1, are encoded by genes arising from the duplication of CCL3 and CCL4, respectively (77).

The genes coding for chemokines MIP- $1 \alpha$ (CCL3) and MIP-1 $\beta$ (CCL4) are clustered together within a $47-\mathrm{kb}$ region on chromosome 17q12 (77). These are potent chemokines produced by a variety of cell types, such as macrophages, NK cells, fibroblasts, and $\mathrm{T}$ cells that stand as natural ligands for the primary HIV-1 co-receptor CCR5 $(8,78)$. These ligands decrease HIV1 R5-trophic infection by desensitizing the CCR5 receptor (79). Saha and collaborators have shown that CD4+ T cells from 6 LTNPs produce high levels of MIP- $1 \alpha$ and MIP- $1 \beta$ in comparison with AIDS subjects, who produce extremely low amounts of these chemokines (80).

One of the isoforms of MIP-1 $\alpha$, the CCL3L1 also known as MIP- $1 \alpha \mathrm{P}$, can physically block HIV-1 entry (81). Variations in CCL3L1 copy number are observed among different ethnic groups; people of African descent have more copies when compared with people of European descent (82). High doses of CCL3L1 could affect HIV-1 infection either by (1) inhibiting HIV-1 gp120 binding to CCR5; (2) reducing CCR5 levels at the cell-surface due to receptor internalization; or (3) affecting leukocyte trafficking important for antiviral responses. However, it seems that chemokine dosage is only significant when compared to the average copy number within an ethnic population. A lower CCL3L1 copy number in one individual, compared with the average copy number in their population, is associated with enhanced susceptibility to HIV-1 infection $(82,83)$. Both CCL3L1 copy number and CCR5-59029 A/G polymorphisms are associated with delayed disease progression among HIV-1 seropositive subjects and repeatedly sexually exposed HIV-1 seronegative individuals from a North Indian population (84).

The RANTES (CCL5) gene is located in chromosome 17, and encodes a chemokine ligand for CCR1, CCR3, and CCR5. This chemokine is able to block the CCR5 co-receptor, inhibit the recycling of internalized CCR5 to the cell-surface, and subsequently suppress HIV-1 infection by R5-strains (8). Thus, some RANTES derivatives, notably N-terminally modified RANTES variants (AOP-, 5P12-, and PSC-RANTES), have been explored as antiHIV molecules (85-87). PSC-RANTES and 5P12-RANTES have been also explored as a topical microbicide, after their antiviral activity was demonstrated in non-human primate models $(88,89)$. Furthermore, three SNPs in this gene $(-28 \mathrm{C}$ to $\mathrm{G}$, $-403 \mathrm{G}$ to $\mathrm{A}$, and $\mathrm{In} .1 .1 \mathrm{C}$ ) were reported to play a role in progression to AIDS. The variant alleles $28 \mathrm{G}$ and $403 \mathrm{~A}$ are associated with delayed progression to AIDS by increasing levels of RANTES transcripts in an Asian population (90, 91). Increased RANTES expression may also contribute to reducing rates of CD4+ T-cell depletion, as it was observed among HIV-infected Japanese individuals (90). Another study on the MACS cohort confirmed the protective role of the 403A allele in disease progression but also described it as a risk factor for HIV transmission (91). However, different results were obtained in a study performed in a Spanish cohort (92), which reflects the controversies around chemokine polymorphisms. These discrepancies may be due to the existence of different allelic frequencies across ethnic groups or to a dominant effect of one variant. For instance, the SNP In.1.1C nested within an intronic regulatory sequence shows the opposite effect of previous alleles, as it accelerates the progression to AIDS in African-Americans and European Americans through downregulation of RANTES transcription (93).

\section{CXCR4 LIGANDS}

The stromal cell-derived factor 1 (SDF-1) (also termed CXCL12) is the only known CXCR4 ligand, and a potent entry inhibitor for X4-tropic HIV-1 strains $(94,95)$. It down-regulates the levels of CXCR4 co-receptor at the cell-surface $(96,97)$. An SDF-1 variant (SDF1-3'A) was identified at position 801 in the $3^{\prime}$ untranslated region ( $3^{\prime} \mathrm{UTR}$ ) of the $\beta$ variant transcript. Conflicting reports exist regarding the role of SDF $1-3^{\prime} \mathrm{A}$ in HIV infection and AIDS. Homozygotes for SDF-3'A progress slower to AIDS in at least three independent studies that analyzed the GRIV cohort, containing 200 non-progressors and 90 fastprogressors; the ALIVE study, containing $2419 \mathrm{HIV}$-1-infected patients and $435 \mathrm{HIV}$-1-exposed uninfected individuals; and a cohort of 12 LTNPs and 12 rapid progressors recruited at the Immunodeficiency Services Clinic at the Erie County Medical Center (98-100). However, other studies found no correlation between the SDF1-3'A allele and disease progression (101-104). Once again the different results obtained in the different studies are probably related to the type of sample, the different readouts and the fact that the $S D F 1-3^{\prime} A / 3^{\prime} A$ effect is recessive, and therefore probably underrepresented in some studies.

\section{CHEMOKINE RECEPTOR-BASED THERAPY}

Therapeutic targeting at an early phase (pre-integration) of the HIV-1 life cycle is expected to be more effective than acting at later stages of viral replication (post-integration). Early-stage intervention could reduce: (1) the integration of HIV into the host's DNA as a provirus, and the subsequent establishment of cellular reservoirs of latent virus; and (2) the emergence of viral resistance due to viral mutations. 
Table 1 | CCR5-directed therapies.

Entry inhibitors

\begin{tabular}{|c|c|c|}
\hline Inhibitor & Development phase & Reference \\
\hline \multicolumn{3}{|c|}{ ALLOSTERIC INHIBITORS } \\
\hline $\begin{array}{l}\text { Aplaviroc } \\
\text { (GW873140) }\end{array}$ & $\begin{array}{l}\text { Terminated at phase } 2 \mathrm{~b} \\
\text { (idiosyncratic hepatotoxicity) }\end{array}$ & Nichols et al. (105) \\
\hline $\begin{array}{l}\text { Vicriviroc } \\
(\mathrm{SCH}-417690, \\
\mathrm{SCH}-\mathrm{D})\end{array}$ & $\begin{array}{l}\text { Stopped at phase } 3 \text { (failure to } \\
\text { demonstrate superiority to } \\
\text { optimized background therapy) }\end{array}$ & Caseiro et al. (106) \\
\hline $\begin{array}{l}\text { Cenicriviroc* } \\
\text { (TBR-652) }\end{array}$ & Phase 2 & $\begin{array}{l}\text { Klibanov et al. (107), } \\
\text { Lalezari et al. (108), } \\
\text { and Marier et al. (109) }\end{array}$ \\
\hline $\begin{array}{l}\text { Maraviroc } \\
(U K-427857)\end{array}$ & FDA approved & \\
\hline \multicolumn{3}{|c|}{ COMPETITIVE INHIBITORS } \\
\hline AOP-RANTES & Pre-clinical & Toossi et al. (87) \\
\hline PSC-RANTES & Pre-clinical & Hartley et al. (86) \\
\hline 5P12-RANTES & Pre-clinical & Gaertner et al. (85) \\
\hline PRO140 & Phase 2 & Jacobson et al. (110) \\
\hline
\end{tabular}

${ }^{*}$ Dual CCR5/CCR2 antagonist.

The observation that CCR $5 \Delta 32$ delays or prevents HIV-1 infection without affecting health encouraged the development of related anti-AIDS therapeutic strategies, from the disruption of the virus-CCR5 interaction to the inhibition of expression of functional CCR5 co-receptors (summarized in Tables 1 and 2). Both competitive and allosteric entry inhibitors have been designed to disrupt the binding of the virus to CCR5. Competitive inhibitors developed include derivatives of natural ligands of CCR5 (RANTES) and anti-CCR5 monoclonal antibodies. Beyond their ability to compete with the viral Env protein for CCR5 binding, chemokine derivatives can also exert their antiviral activity by inducing internalization of CCR5 from the cell-surface (111). However, one drawback of CCR5 ligand derivatives is the undesired agonistic effect on CCR5. Allosteric inhibitors are small molecules that do not compete with the virus to bind CCR5. Instead, upon binding to a hydrophobic pocket in the transmembrane domain of CCR5, they induce a conformational change of the extracellular loops required for HIV entry. This different approach to inhibit HIV-1 entry has been shown to be very successful giving rise to several compounds that efficiently inhibit HIV-1 replication in vitro and in vivo (Table 1), including maraviroc and enfuvirtide, the two entry inhibitors approved by the FDA for HIV1 -infected patients (112). Monoclonal antibodies, engineered to block HIV-1 infection without affecting CCR5-mediated signaling, can be administered less frequently than chemokine derivatives and small-molecule inhibitors. The PRO140 monoclonal antibody, for example, has been demonstrated to significantly reduce viral load of patients $(110,113)$.

In addition, several gene therapy (GT) approaches have been developed to inhibit CCR5 expression. CCR5 expression has been successfully repressed in different models at a gene-editing level by means of zinc-finger nucleases (ZFN); at the RNA level by means of RNA interference or ribozymes (RZB); and at the protein level
Table 2 | CCR5 gene therapy strategies.

CCR5 gene therapy

\begin{tabular}{lll}
\hline GT mechanism & Development phase & Reference \\
\hline siRNA-mediated knockdown & Pre-clinical & Kim et al. (115) \\
shRNA-mediated knockdown & Pre-clinical & Shimizu et al. (120) \\
RBZ- mediated knockdown & Pre-clinical & DiGiusto et al. (114) \\
ZFN-gene-editing & Phase 1/2 & Clinicaltrials.gov \\
& & NCT00842634 \\
& & NCT01252641 \\
& & NCT01044654 \\
\hline
\end{tabular}

by means of intrabodies (114-117) (Table 2). The possible efficacy of CCR5-targeting GT to cure AIDS has been strongly supported by the results of the "Berlin patient" who still has no detectable HIV-1 after receiving a hematopoietic stem/progenitor cell (HSC) transplantation from a CCR5 $\Delta 32$ HLA-matched donor 6 years ago despite discontinuing antiviral therapy $(118,119)$. Of note, the risks associated to allogenic (i.e., from donors) transplantation, which implicates chemotherapy and radiation, and the low number of CCR $5 \Delta 32$ homozygotic HLA-matched donors limits the widespread application of this approach. Alternative strategies are to create autologous (i.e., self-donation) $\mathrm{CCR} 5^{-l-}$ stem cells or CD4+ T cells to be engrafted to the patients. RNAi-based therapies can be achieved either by delivery of siRNA, with a transient effect, or by shRNA lentiviral vectors with stable effects. Both strategies have been shown to be valid. Specific delivery of siRNA against CCR5 to T cells and macrophages by nanoparticles via an antibody to the LFA-1 integrin reduced HIV-1 loads and CD4+ T cell loss in humanized BLT mice (115). Inhibition of HIV-1 replication was also observed ex vivo in differentiated spleenocytes from BLT mice engrafted with human CD34+ HSCs transduced with anti-CCR5 shRNA (120). To maximize the blockage of HIV-1 replication, vectors that combine anti-CCR5 shRNA with other therapeutic targets, like TRIM5 $\alpha$ (discussed below), have been tested. A combinatorial lentiviral vector with a CCR5 ribozyme, Tat/Rev shRNA, and a TAR decoy was tested in AIDS lymphoma patients (114). The non-toxic expression of vector, shRNA, and ribozyme 24 months following autologous, gene-modified HSC transplantation, established that this therapeutic approach was safe. However, in vivo efficacy remains to be proven. Although encouraging results have been reached with these GT approaches, these vectors can be associated with genotoxicity and malignancy. Therefore, the safety of the integrative vector systems needed for stable transgene expression needs to be optimized. These vectors can integrate in undesired places of the host's genome, inactivating essential genes or activating deleterious genes, such as proto-oncogenes. Additionally, sufficient levels of anti-CCR5 activity need to be reached and maintained. Geneediting with ZFNs has been tested to overcome these problems. ZFNs are engineered proteins composed by a DNA-binding zincfinger protein fused to the catalytic domain of a FokI restriction endonuclease (121). Upon binding to the targeted DNA sequence, the ZFN introduces DNA double-strand breaks that are repaired by the error-prone NHEJ repair pathway of the host cell. This 
usually introduces permanent nucleotide insertions and deletions in a gene sequence that will produce a non-functional protein. Thus, ZFNs only need to be transiently expressed to achieve a permanent modification of the CCR5 gene, and this can be achieved by means of standard DNA delivery (nucleofection) or nonintegrating vectors systems. Perez and collaborators reported that a CCR5-targeted ZFN disrupted approximately 50\% of CCR5 alleles in primary human CD4+ T cells (116). By using new immunosuppressed mouse models that widely accept heterologous cells, such as the NOG mouse model [NOD/SCID/IL2rgamma (null)], these CCR5-modified T cells were able to grow stably and block R5-tropic HIV-1 replication both in vitro and in vivo. Disruption of CCR 5 by means of ZFNs has also been achieved ex vivo in human CD34+ HSCs (122). CCR5-modified HSCs retained their ability to engraft NOG mice and displayed normal multi-lineage differentiation. Mice engrafted with CCR5-modified HSC had significantly lower HIV-1 levels and higher CD4+ T cells counts than control mice. The safety and tolerability of CCR5- modified CD4+ $\mathrm{T}$ cells are being tested in one completed and two ongoing clinical trials (Table 2).

\section{RESTRICTION FACTORS}

Restriction Factors (RFs) are cellular proteins that can restrict or block viral replication in a cell-specific way. Generally RFs are not sufficient to block HIV-1 replication as HIV-1 developed several countermeasures to abolish its activity via virus-specific proteins and degradation by the proteasome. RFs are part of the innate immune response and normally respond to Interferon (IFN) stimulation. Several RFs of HIV replication have been identified, which act at several key steps of the HIV-1 life cycle. As RFs naturally control HIV infection, it is conceivable that RF genetic alterations or levels of expression are related to differences in HIV progression. Consequently, RF-based therapeutic strategies can be envisioned to control HIV replication. For an overview of the retroviral life cycle and the RF discussed herein see Figure 2.

\section{APOBEC PROTEIN FAMILY}

Apolipoprotein B-editing catalytic polypeptide 3 proteins (APOBEC3, A3) are members of the cytidine deaminase family that share a common structure. During evolution, several members of the human APOBEC3 gene cluster (A3B, A3DE, A3F, and $\mathrm{A} 3 \mathrm{G}$ ) suffered duplication and/or recombination [reviewed in Conticello (123)]. With the exception of A3C, all members of the A3 family have anti-retroviral activity.

APOBEC protein expression and activity must be strictly regulated in order to maintain genome stability and cellular metabolism, as overexpression leads to the appearance of cancer (124). A3G and A3F are highly potent single-stranded DNA (ssDNA) cytidine deaminases. These editing enzymes likely evolved to control the replication of endogenous retroelements and exogenous retrovirus, including HIV-1. A3G specifically restricts the replication of incoming viruses in resting CD4 $\mathrm{T}$ cells and monocyte-derived macrophages (MDM cells) (125-127). A3G and A3F activity is mainly regulated through their association with other cellular factors, and switches from an active low-molecular-mass (LMM) ribonucleoprotein complex to an inactive high-molecular-mass (HMM) complex (128). Their activity can also be modulated by other complementary mechanisms, including tissue- and stage-specific signaling, transcriptional regulation, subcellular localization, posttranslational modifications, interaction with specific cofactors, and accessibility of the target sequence [reviewed in Smith et al. (129)].

Both A3G and A3F RF need to be incorporated into the viral particle to be capable of exerting their restriction phenotype in the target cell $(130,131)$. However, recent studies indicate that A3G does not always need to be packaged in the viral particle to exert its antiviral function, as endogenous LMM A3G can restrict $\mathrm{HIV}$ in resting CD4 T cells $(132,133)$. A3G antiviral activity can either be deaminase-dependent or deaminase-independent. For deaminase-dependent activity, A3G exerts its action in target cells during reverse transcription of the growing minus
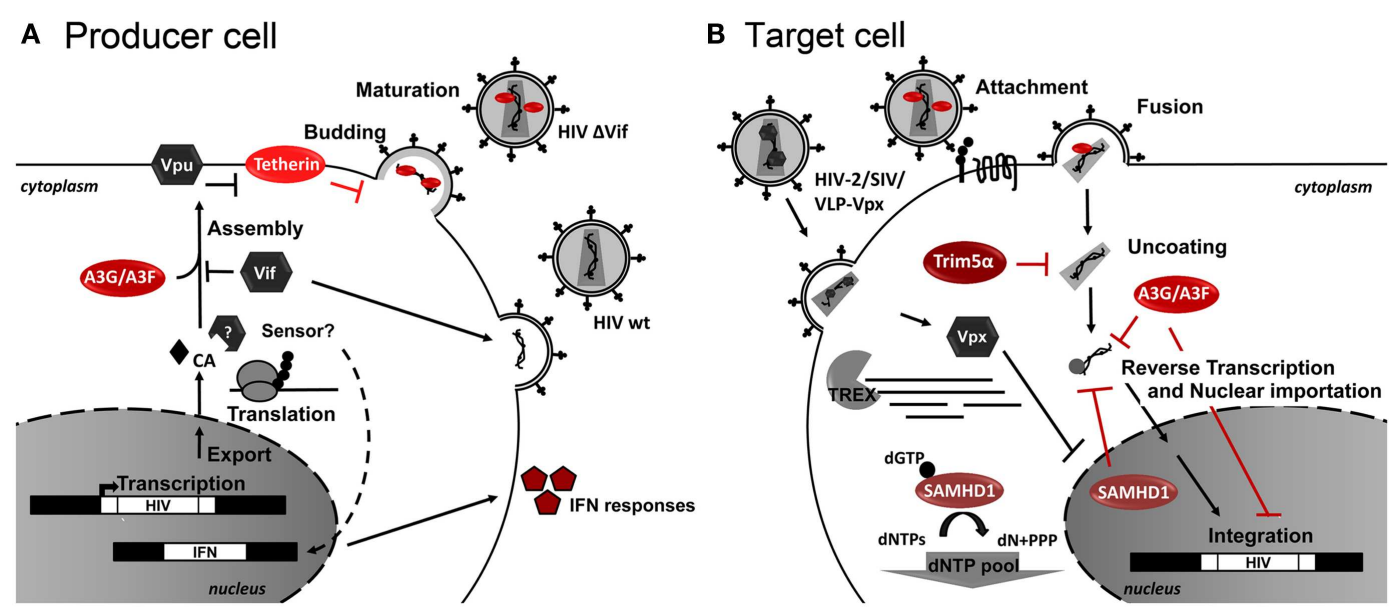

FIGURE 2 | Host restriction factors and their action during HIV-1

replication. Schematic representation of (A) HIV-1-infected producer cell, and (B) HIV-1 target cell. Cellular restriction factors are represented by red ovals, and viral counterpartners are represented by gray hexagons. Black arrows represent the course of viral replication and actions. Broken arrows represent inhibition. Question marks (?) represent unresolved questions. 
strand of viral DNA, which is deaminated independently of the reverse transcriptase $(134,135)$. The resulting dU-rich transcripts have two possible fates. They are either degraded by the cellular uracyl-DNA-glycosylase (UDG), causing the failure of reverse transcription $(136,137)$, or yield G-to-A hypermutated proviruses that are largely non-functional, with the consequent reduction in viral fitness $(125,134,138-141)$. More recently, the deaminase-independent restriction activity of $\mathrm{A} 3 \mathrm{G}$ against HIV-1 was discovered as cells bearing catalytically inactive A3G mutants kept their ability to block HIV-1 infection (142, 143). In addition, A3G inhibits several steps of viral cDNA synthesis and integration by: (1) reducing the efficiency of plus-strand transfer (144); (2) reducing tRNALys3-priming and initiation of viral DNA synthesis (145-147); and (3) interfering with reverse transcription, DNA elongation, and proviral integration (146, 148-150). A3F showed similar, but more pronounced, effects on HIV-1 infection (149-152).

HIV escapes the cellular restriction exerted by A3G and A3F by expressing the viral infectivity factor (Vif) (153-155). Vif specifically depletes A3G and A3F from the virus-producing cells by inducing its proteasomal degradation (137, 156-161). Vif is part of the RING-finger E3-ubiquitin complex with Elongin B (EloB) and $\mathrm{C}$ (EloC), Cullin 5 (Cul5), and Ring-box protein 2 $(\mathrm{Rbx} 2)$ and the recently identified core-binding factor $\beta(\mathrm{CBF}-\beta)$ (162-165). Vif also reduces A3G translation (131) and competes or directly blocks A3G viral incorporation (166-168), besides blocking A3G catalytic activity (169). A3G overexpression overcomes the action of Vif-positive viruses (159), indicating that higher A3G expression is responsible for the high-incidence of G-A mutations in the proviral DNA from many HIV-1-infected subjects, even in the presence of Vif $(157,170-175)$. This A3-mediated hypermutation of the proviral genome can confer a selective advantage or disadvantage for viral replication (176) and result in the appearance of either more virulent or innocuous strains $(173,174,177)$.

\section{APOBEC CLINICAL STUDIES}

Population-based studies have tried to establish a relationship between A3 polymorphisms, expression, and/or activity and the rate of disease progression (174, 175, 178-182). However, the different experimental setups and readouts, sample size, types of populations, host, and viral specific genetics and analysis contribute to data entropy and inconsistent results. An A3G polymorphism identified (H186R or rs8177832) in African-Americans and the 6,892C allele present in European-American populations were associated with accelerated disease progression $(174,178,181)$. Nevertheless, protective A3G or A3F polymorphisms have yet to be identified. An extensive study where the genetics of the GRIV cohort were analyzed led to the identification of several new SNPs in APOBEC3G. However, none of them presented any association with AIDS progression in this cohort (183). In other studies, A3G/A3F mRNA levels were measured as a readout of A3G/A3F expression in activated cells $(179)$ or in non-activated cells $(181,184)$, and they were compared with markers of disease progression such as viral load and CD4+ T cell counts (179-181, 185, 186). They found an inverse correlation between $\mathrm{A} 3 \mathrm{G}$ mRNA levels and disease progression in LTNPs (179), but not in progressors (184). Other groups measured proviral genome hypermutation as a readout for A3G/A3F activity $(174,187-189)$. Some studies found a correlation between hypermutation and high CD4+ T cell counts (188) or reduced plasma RNA levels (174), while another report did not find any relationship between hypermutation and either viral load or CD4+ T cell counts (189). In addition, a study comparing elite suppressors and patients under antiviral treatment showed no statistical differences between their hypermutation frequencies (187). As deamination is not the sole A3 antiviral mechanism, deamination (catalytic activity) might not represent A3G/A3F antiviral activity properly and might explain the different conclusions obtained from different studies. For instance, studies on elite suppressors showed that these subjects have lower levels of integrated proviral DNA and generated more proviral 2-LTR forms than HIV-1 patients on treatment, probably due to cell-specific, integrase-independent mechanisms $(190,191)$. More recently, a study with 19 anti-retroviral-naïve HIV-positive patients [12 LTNP ( $<5000$ RNA copies/ml over the prior 5 years) and seven non-controllers $(>10000$ copies $/ \mathrm{ml})]$ established a relationship between the control of HIV-1 infection by elite suppressors and A3G and A3F expression and activity (192).

These observations support the possible use of pharmacological modifiers of A3 expression as an alternative strategy to increase the natural protection against HIV replication. The upregulation of A3G expression can be mediated by the stimulation of CCR 5 and CD40 (part of a major co-stimulatory pathway) with CCL3 and CD40L (CD154) chemokines, respectively, as well as by the heat shock protein 70 (HSP70). In fact, the use of HSP70 as a preventive measure was already tested in rhesus macaques with success (193). CCR6 ligands also increase the natural protection of CCR6+ cells against HIV by inducing A3G expression (194). Since the A3G activity is tightly regulated in the HMM complexes, an increase in A3G expression might not be enough to overcome HIV replication in all cells. Thus, the use of HMM inhibitors might serve as a complement to this strategy, as they would activate A3G $(125,127$, 133). However, these strategies must be strictly regulated to avoid unwanted side-effects.

The Vif-A3G, Vif-Cullin5, or Vif-CBF- $\beta$ interaction sites are also promising sites for the development of new anti-HIV molecules such as the RN-18 $(195,196)$ or the 4BL intrabody (197), that specifically target the HIV-1 Vif protein. However, drugs that specifically interfere with A3G degradation by targeting Vif cellular partners are preferable to avoid the generation of resistant mutants, e.g., the IMB-26/35 small molecules that bind A3G and block its Vif-mediated degradation (198). Alternative strategies to inhibit HIV by enhancing viral incorporation of A3G into HIV1 Vif + viral particles have been tested: theVpr14-88-Apobec3G fusion protein strategy (199) and the Nef7-A3G fusion protein strategy (200). More recently, the use of Chim3, a Vif-dominant negative protein, was shown to block HIV-1 replication by acting at the pre-integration step of HIV-1 (201).

\section{TRIPARTITE MOTIF FAMILY PROTEINS}

The TRIM family includes approximately 100 proteins characterized by a highly conserved tripartite motif (TRIM) structure on their amino-terminal region, called RBCC motif. This 
motif is constituted by a RING (Really Interesting New Gene) domain, one or two B-box domains and a coiled-coil domain (CC) (202). The RING domain is a zinc-binding motif with E3-ubiquitin ligase activity which mediates the conjugation of proteins with ubiquitin, small ubiquitin-like modifier (SUMO), or with the ubiquitin-like IFN-stimulated protein of $15 \mathrm{kDa}$ (ISG15) (203). The B-box domains are zinc-finger proteins. The CC is a helical structure important for homo- or heteromeric interactions that lead to the formation of high molecular-mass complexes that could determine the function of TRIM proteins. The diversity of the TRIM family results from the 10 different C-terminal domains that can be found alone or in combination allowing TRIM proteins to be classified in 11 different classes (204). Two of the most common C-terminal domains are the PRY and SPRY domains, which can combine to form a PRYSPRY domain (also known as B30.2). TRIM proteins are involved in several biological processes such as innate immunity, cell differentiation, and transcriptional regulation (203,205). Several TRIM family members have been identified as HIV-1 RF acting at different steps in the HIV-1 life cycle, namely TRIM5, TRIM11, TRIM15, TRIM19, TRIM22, TRIM31, and TRIM32. However, the TRIM5 proteins are the best studied.

TRIM5 is expressed along the primate lineage and is encoded by the TRIM5 gene. This gene codes for different TRIM5 isoforms, amongst which only TRIM5 $\alpha$ and TRIM5Cyp show antiviral properties $(206,207)$. TRIM5Cyp from the New World Owl monkey is structurally different from TRIM5 $\alpha$ at its C-terminal end, containing a cyclophilin A domain instead of the PRYSPRY domain present in the $\alpha$ isoform. Primate TRIM5 $\alpha$ orthologs inhibit several retroviruses and lentiviruses but are ineffective against their own host-specific viruses. For example, while human TRIM5 $\alpha$ (huTRIM5) strongly restricts N-tropic murine leukemia virus (N-MLV), it only weakly restricts HIV-1 infection. Rhesus monkey TRIM5 $\alpha$ (rhTRIM5) efficiently blocks HIV-1 but not the infection by the autologous simian immunodeficiency virus (SIV MAC) (207-209).

It is well-established that TRIM5 proteins block HIV-1 infection at an early-stage of reverse transcription but their exact antiviral mechanism remains unclear. TRIM5 proteins bind to the HIV-1 capsid (CA) and induce its premature disassembly before reverse transcription can occur (207). The biochemical interactions between the CA and TRIM5 proteins are complex and important for their restriction activity. They involve: (1) the binding of their C-terminal domain (B30.2 domain for TRIM5 $\alpha$ and cyclophilin A for TRIM5Cyp) to the CA lattice (206, 210-212); and (2) the dimerization and higher-order multimerization of TRIM5 (213-215), which ultimately leads to the formation of an hexameric protein lattice (216). Both coiled-coil and Bbox 2 domains of TRIM5 are required for its dimerization and multimerization $(213,217-219)$. In addition to a direct antiviral mechanism, it has been suggested that TRIM5 acts as a pattern recognition receptor that "senses" the CA lattice, leading to the activation of the innate immune response (220). This CA sensing triggers the E3-ubiquitin ligase activity of the RING domain of TRIM5 proteins that, together with the heterodimeric E2 Ubiquitinconjugating enzyme complex UBC13-UEV1A, generate unattached K63-linked ubiquitin chains, leading to its multimerization and the activation of the TAK1 kinase complex. Subsequently,
TAK1 activates NF- $\kappa$ B and AP-1 signaling (220). However, the exact contribution of innate immune response and E3-ubiquitin ligase activity in TRIM5 antiviral activities still needs to be evaluated. Deletion of the RING domain only partially abrogates restriction of HIV-1 by TRIM5 proteins $(211,221)$ and while proteasome inhibitors prevent TRIM5 blockade on CA disruption and reverse transcription, they do not affect TRIM5 antiviral activity $(222,223)$.

\section{TRIM5 $\alpha$ GENETIC-VARIANTS CLINICAL STUDIES}

Several studies have addressed the relationship between huTRIM5 $\alpha$ and its genetic-variants and HIV disease progression to AIDS. However, this is still a controversial subject. The huTRIM $5 \alpha$ gene has several SNPs but only two of them have been studied for their effect on disease progression (H43Y huTRIM5 $\alpha$ and R136Q huTRIM5 $\alpha$ ) $(224,225)$. The huTRIM5 $\alpha$ H43Y polymorphism occurs at the RING domain of TRIM5 $\alpha$ and may therefore affect its E3-ubiquitin ligase activity (225). In vitro assays showed that the $43 \mathrm{Y}$ variant exhibits an antiviral activity lower or similar to the $43 \mathrm{H}$ variant (224-227). However, the discrepancies among these studies could be due to the different expression systems used, as the H43Y polymorphism shows protective effects against HIV-1 infection in African-Americans and Chinese intravenous drug users $(226,228)$. However, other epidemiological studies failed to correlate the $\mathrm{H} 43 \mathrm{Y}$ polymorphism with resistance to HIV-1 infection or AIDS progression $(224,226,227,229)$. Likewise, and consistent with its lower in vitro antiviral activity, a $\mathrm{H} 43 \mathrm{Y}$ homozygous genotype is predictive of an accelerated progression to AIDS (230). As the H43Y polymorphism results in different protective effects in different populations, it is conceivable that the genetic background may account for these conflicting results among epidemiological studies. The other huTRIM $5 \alpha$ polymorphism (R136Q) occurs at the CC which is, as mentioned, important for TRIM5 protein oligomerization and antiviral activity. The antiviral activity of the 136Q variant is higher than $136 \mathrm{R}$ which is consistent with the HIV-1 protective effect observed in both US-based natural history and Pumwani sex workers cohort studies $(226,229)$. However, this protective effect appears to be dependent on the strain of HIV, as it was only observed after the emergence of X4-strains and not with R5-strains (230). Conversely, Goldschmidt and co-workers were unable to correlate the R136Q polymorphism with disease progression (224). Thus, besides the strong significance of TRIM5 proteins as antiviral factors, more data on genetic polymorphisms needs to be gathered and analyzed in large cohorts. This assumption is crucial to determine the species-specific activity of TRIM5 proteins and how they relate to the innate immunity of different populations.

\section{TRIM5 $\alpha$-BASED THERAPIES}

TRIM5 $\alpha$ is an attractive cellular host protein for HIV-1 gene-based therapies as it acts at a post-entry level, which is a therapeutic advantage as already mentioned. A pioneer study by Anderson and Akkina (231) showed that human macrophages differentiated in vitro from $\mathrm{CD} 34^{+} \mathrm{HSCs}$ and transduced with rhesus macaque TRIM $5 \alpha$ resisted HIV-1 infection, thus providing the proof of principle that TRIM5 $\alpha$ could be used in gene therapy. However, since rhTRIM5 is not human, it would likely elicit an undesirable 
immune response. On the other hand, the use of human TRIM5 $\alpha$ would not trigger these immune responses, but unfortunately it has less potent antiviral activity. To overcome these limitations the hTRIM $5 \alpha$ has been engineered. One strategy was to construct a chimeric human-rhesus (HRH) isoform that contains the rhesus macaque TRIM5 $\alpha 13$ aa sequence in place of the human 11 aa region located in the PRYSPRY domain (232). CD34+ HSC transduction with this HRH chimeric isoform originated normal macrophages in vitro, normal $\mathrm{T}$ cells in vivo, and hindered HIV-1 infection of CCR5- and CXCR4-tropic HIV-1 clones. To further increase the efficacy of HIV-1 gene therapy, Anderson and collaborators combined the HRH chimeric isoform with two other transgenes that act at different stages of the HIV-1 life cycle: a CCR5 shRNA (pre-entry) and a Transactivation response element TAR decoy (post-integration) (233). This anti-HIV-1 vector displayed complete protection from productive viral infection and integration of multiple HIV-1 strains upon transduction into HIV target cells in vitro (233) NOD-RAG1 ${ }^{-1-}$ IL $2 \mathrm{r}^{-1-}$ mice [immunodeficient mice carrying mutations in the recombination activating gene-1 (Rag1 $\left.{ }^{\text {null }}\right)$ and interleukin (IL)-2 receptor common gamma chain $\left.\left(I L 2 r \gamma^{n u l l}\right)\right]$ were engrafted, with CD34+ HSCs and transduced with the anti-HIV vector described above. They exhibited normal multi-lineage hematopoiesis and no decrease on human CD4+ T cells levels upon infection with R5 and X4tropic strains of HIV-1 (234). However, the latter observation was not accompanied by a decrease of plasma viremia, and blockade of HIV-1 infection was only observed in ex vivo experiments. Another promising engineered human TRIM5 $\alpha$ protein is huTRIM5Cyp, a design inspired by TRIM5Cyp from New World owl monkey, a potent inhibitor of HIV-1 replication (235). This molecule, resulting from the fusion of human TRIM $5 \alpha$ and human CypA, blocked CCR5-, and CXCR4-tropic HIV-1 clones and primary isolates of HIV-1 replication in several cell types, including CRFK, Jurkat, and primary $\mathrm{T}$ cells (CD4+ $\mathrm{T}$ cells and macrophages). HIV-1 infection was also impaired in other humanized immunodeficient mouse line, the NOD-RAG $2^{-l}-\gamma \mathrm{c}^{-/-}$strain, when these mice were engrafted with CD4+ T cells or CD34+ HSCs transduced with huTRIM5Cyp (235). Interestingly, a higher restriction in HIV-1 infection was achieved by engrafting mice with transduced CD4+ $\mathrm{T}$ cells than with transduced CD34+ HSC cells. Additionally, a functional screening of huTRIM $5 \alpha$ mutants generated by PCRbased random mutagenesis identified that an R335G mutation efficiently prevented HIV-1 infection in vitro (236). Additionally, a functional screening of huTRIM $5 \alpha$ mutants generated by PCRbased random mutagenesis identified that an R335G mutation efficiently prevented HIV-1 infection in vitro (236). Thus, novel huTRIM $5 \alpha$ proteins with few mutations could be engineered to effectively inhibit HIV-1 infection with limited immunogenicity. Mutations could also be achieved in vivo by using ZFN as described above for the CCR5 receptor. Overall, these encouraging results confirm the potential of TRIM5 $\alpha$ and gene therapy approaches to treat HIV-1 and pave the way for clinical studies, which, to our knowledge, are not underway.

\section{TETHERIN}

Tetherin (BST-2/CD317/HM1.24) is a type 2 transmembrane protein anchored by a transmembrane domain near the $\mathrm{N}$-terminus and a glycosylphosphatidylinositol (GPI) anchor at the C-terminal that may be a second transmembrane domain $(237,238)$. This protein is also composed of an N-cytoplasmic tail and an ectodomain that links the two anchors. Through its GPI anchor, tetherin is located in lipid rafts at the plasma membrane, trans-Golgi Network (TGN), and early and recycling endosomes (238-241). The ectodomain contains an $\alpha$-helical coiled-coil region with cysteine residues that allow the formation of parallel homodimers by disulfide bonds (242-244). The coiled-coil region has structural irregularities believed to provide conformational flexibility (244, 245). Crystal resolution also showed that two tetherin dimers could associate to form a tetramer $(243,244)$.

Tetherin is constitutively expressed in mature B cells, bone marrow stromal cells, plasma cells, plasmacytoid DC, and some cancer cell lines $(242,246)$. Its expression can also be induced in several cell lines following stimulation with type-I IFN, IFN- $\gamma$, or other pro-inflammatory stimuli $(242,246-249)$. Tetherin's cellular expression pattern suggests a role in the development of pre-B cells and tumor invasion. Recently, it was proposed to negatively regulate IFN production by binding to immunoglobulin-like transcript 7 (ITL7) in plasmacytoid DC (250). However, probably the best established physiological function of tetherin is its antiviral activity against various virus families.

Tetherin was first identified as the cellular factor responsible for the inhibition of the spread of $v p u$-defective HIV-1 mature virions, by preventing their release from the cell $(251,252)$. Tetherin exhibits an antiviral activity against a wide range of enveloped viruses as its main target is the lipid bilayer derived from the host cell (253). Tethered viral particles can remain at the cell-surface or suffer endocytosis and potentially be degraded in a process promoted by Rabring7 (254). It has also been suggested that these tethered virus could influence the cell-to-cell virus transmission which occurs through virological synapses. While two in vitro studies reported that tetherin is capable of decreasing cell-to-cell transmission, a third one describes the opposite effect (255-257). A recent in vivo study where tetherin reduces viral burden and inhibits pathogenesis supports the hypothesis that tetherin does not favor cell-to-cell transmission (258). However, more studies are needed to clarify the role of tetherin in cell-to-cell transmission in vivo.

Several observations strongly support that tetherin prevents virion release through a direct mechanism, which involves a physical binding between the host cell and the virion (Figure 3A). First, tetherin was shown to localize between the cell and the virion $(239,259-261)$. Secondly, its antiviral activity could be mimicked by a synthetic protein, with low amino acid sequence similarity but similar topology containing two-membrane anchors at either end and a coiled-coil ectodomain in between (261). Two topological models for tethering activity are suggested (Figure 3B) [reviewed in Kuhl et al. (262)]. Viruses escape tetherin restriction in a species-specific manner. Vpu is the HIV-1 viral antagonist of tetherin $(251,252)$. This viral protein is a small transmembrane protein that interacts with tetherin, through its respective transmembrane domains, trapping it at the TGN or targeting it for degradation through proteasomal or lysosomal pathways (263268). Both situations lead to a decrease of tetherin levels at the plasma cell membrane and thus at the HIV-1 assembly sites. HIV-2 lacks Vpu, but it counteracts tetherin antiviral activity through its Env protein in a similar way. HIV-2 Env diminishes tetherin levels 


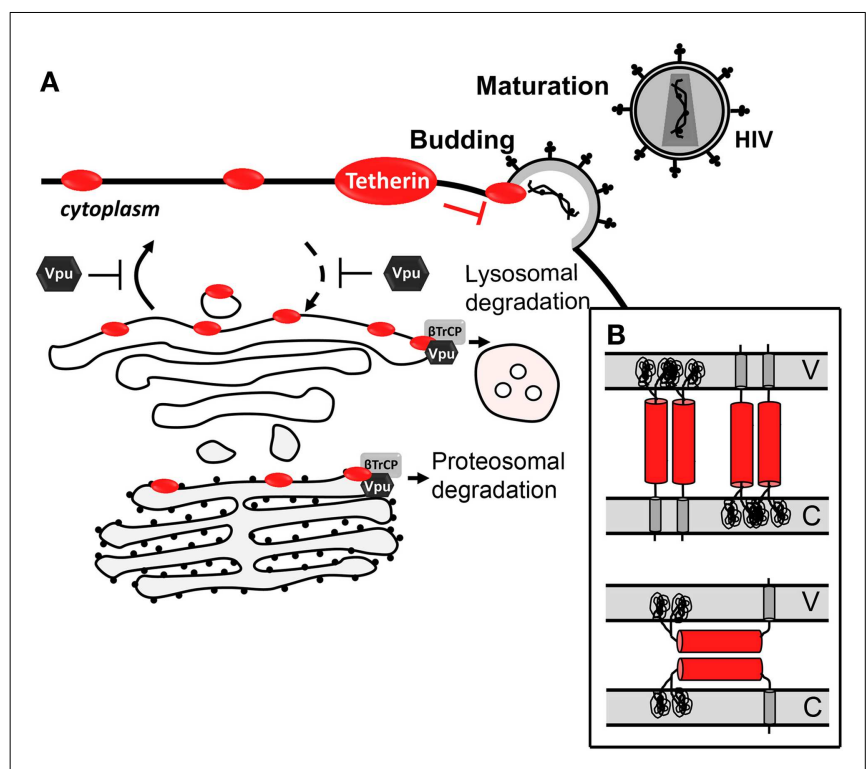

FIGURE 3 |Antiviral mechanism of tetherin. (A) Tetherin prevents Vpu-defective virus release by tethering newly formed virus to the cell-surface. Vpu counteracts tetherin by trapping it at the TGN or targeting it for proteasomal or lysosomal degradation. (B) Topological models for antiviral tetherin mechanisms. One end of tetherin is anchored at the cell plasma membrane and the other end is anchored at the surface of the virion (top); or both ends of one monomer of tetherin parallel homodimers are inserted in either the cell plasma membrane or the viral membrane (bottom). V stands for viral membrane and $\mathrm{C}$ stands for cellular membrane.

at the plasma membrane by sequestering it at the TGN, while the total cellular levels of tetherin remain unaltered $(269,270)$. Besides HIV-1 Vpu and HIV-2 Env, SIV Env, SIV Nef, SIV Vpu, KSHV K5, and Ebola envelope glycoprotein have also been shown to thwart tetherin through distinct mechanisms (253).

\section{TETHERIN CLINICAL STUDIES AND TETHERIN-BASED THERAPEUTICS}

With few clinical studies on tetherin, its impact in disease progression and in LTNPs is still largely unknown. So far, no significant differences in tetherin expression levels were found between HIV-1-exposed seronegative subjects and healthy controls (271). However, tetherin expression was shown to be increased in mononuclear leukocytes, including $\mathrm{CD}^{+} \mathrm{T}$ lymphocytes, from untreated HIV-positive patients when compared to cells of uninfected controls during the acute phase of infection $(271,272)$. This increase was more pronounced during the acute phase of infection (272). In addition, it was also reported that subjects under antiretroviral treatment, who present reduced viremia, also exhibit total tetherin protein levels similar to those observed in uninfected controls $(271,272)$. Altogether, these observations suggest that tetherin, as an interferon-stimulated gene, can be involved in the control of the acute phase of infection. However, as the disease progresses it becomes inefficient. A role of tetherin in IFN- $\alpha$ pathway in HIV-1 infection is further supported by the observation that pegylated IFN- $\alpha$ /ribavinin combination therapy for HIV/hepatitis $\mathrm{C}$ virus co-infected individuals decreased HIV-1 viral load, which is correlated with an increase in tetherin levels in CD4 ${ }^{+} \mathrm{T}$ cells (273). The notion that tetherin is a part of the IFN pathway to control HIV infection in vivo was further investigated in vitro. PBMCs treated with IFN- $\alpha$ show an increase in the expression of tetherin to levels high enough to counteract the Vpu protein, resulting in the viral tethering that blocks the release of wild type HIV virions (272). In vitro and in vivo results led to the proposal that induction of tetherin expression may be a valid therapeutic approach in the fight against AIDS $(272,273)$. The easiest way to induce tetherin expression would be to treat patients with IFN- $\alpha$. However, not only is IFN- $\alpha$ treatment accompanied by several side-effects, it was also associated with an increase in AIDS progression (274). A more effective and safer therapeutic approach should not increase tetherin expression levels, but, rather, increase its functional levels at the cell-surface by competitively inhibiting its interaction with $\mathrm{Vpu}$. This could be achieved by peptides or other type of molecules with higher affinity for the transmembrane domain of Vpu than the transmembrane domain of tetherin. This therapeutic strategy has now been supported by a recent in vitro study, where the expression of the tetherin delGPI mutant inhibited the release of HIV-1 wild type from tetherin-positive HeLa cells by competitively inhibiting the interaction of $\mathrm{Vpu}$ with endogenous tetherin through its transmembrane domain (275). In vitro and in vivo studies with other inhibitors should now follow to fully understand if inhibition of $\mathrm{Vpu} /$ tetherin interaction is a viable therapeutic approach to control HIV spread in infected individuals.

\section{SAMHD1}

The sterile alpha motif (SAM) and histidine-aspartate (HD) domain-containing protein 1 (SAMHD1) contains a SAM and a HD domain in tandem. SAM domain-containing proteins putatively interact with other proteins and RNA $(276,277)$. The SAM domain of SAMHD1 protein harbors a nuclear localization signal $\left({ }^{11} \mathrm{KRPR}^{14}\right)$ within the first 15 amino acids of the protein sequence that specifically localizes SAMHD1 to the nucleus (278280). However, SAMHD1 also localizes in the cytoplasm of resting and activated CD4 T cells and macrophages $(281,282)$. The HD domain is found in a superfamily of proteins with a metaldependent phosphohydrolase activity (283). Enzymatic and structural studies showed that this domain is the sole determinant of the activity, oligomerization and RNA binding activity of SAMHD1 $(280,284)$. SAMHD1 is expressed in a variety of tissues at different levels. It is highly expressed in myeloid-derived cells, such as monocytes, macrophages, DC, and resting CD4 T cells (naïve, central memory, and effector memory). These cells are highly refractory to HIV-1 infection, supporting the role of SAMHD1 as a RF. SAMHD1 expression is independent of the cell activation state (281), is inducible by type-I IFN in monocytes (285) and is transiently sensitive to type-I IFN in DC (286). The transient response of DC to type-I IFN consists of an increase in SAMDH1 mRNA levels early after IFN treatment that do not result in protein expression (286). SAMHD1 appears to be part of an immune evasion strategy to escape antiviral responses mediated by the detection of dsDNA by dsDNA-sensors (dsDNA-sensor antiviral responses). SAMHD1 is a deoxynucleotide triphosphate (dNTP) hydrolase that is activated by the binding of GTP to its allosteric site, cleaving dNTPs into deoxynucleoside and triphosphate products (284, 
287). Consequently, SAMHD1 reduces the intracellular dNTP pool below levels that support HIV-1 reverse transcription, blocking HIV-1 replication and avoiding the induction of IFN responses (281, 288-290). This phenotype can be reverted by addition of deoxynucleotides to the culture medium or by transduction of cells with the HIV-2 accessory protein-Viral Protein X (Vpx). In cellular models using primary SIV, SAMHD1 restriction can also be overcome by transduction of cells with the Viral Protein R (Vpr) $(289,290)$.

$\mathrm{Vpx}$ is a small lentiviral accessory protein with $12-16 \mathrm{kDa}$ that is packaged into the budding virion during assembly, allowing it to act on newly infected cells prior to proviral integration. In the host cell, $\mathrm{Vpx}$ is translocated into the nucleus, where it associates with the cullin-4A-ring-E3-ubiquitin ligase (CRL4) (Figure 4). The formation of this complex leads to degradation of SAMHD1 restriction factor by the $26 \mathrm{~S}$ proteasome (281). While SAMHD1 activity as a restriction factor is independent of its subcellular location, Vpx is ineffective against cytoplasmic SAMHD1 (279). SAMHD1 proteosomal degradation causes an indirect increase in the intracellular pool of dNTPs, allowing HIV-1 reverse transcription and the infection of cells that are otherwise very resistant to the virus. For example, full-length viral cDNA accumulates in resting CD4 T cells and HIV-1 infectivity is restored in monocyte-derived macrophages (MDMs) and DC cells upon Vpx expression and SAMHD1 degradation (279, 281, 286, 288292). However, these cells possess an unknown sensor in their cytoplasm that detects newly synthesized viral proteins and triggers IFN responses (293). Therefore it is conceivable that HIV-1 did not evolve an anti-SAMHD1 counteracting protein to avoid the cellular detection of viral proteins and consequent immune activation.

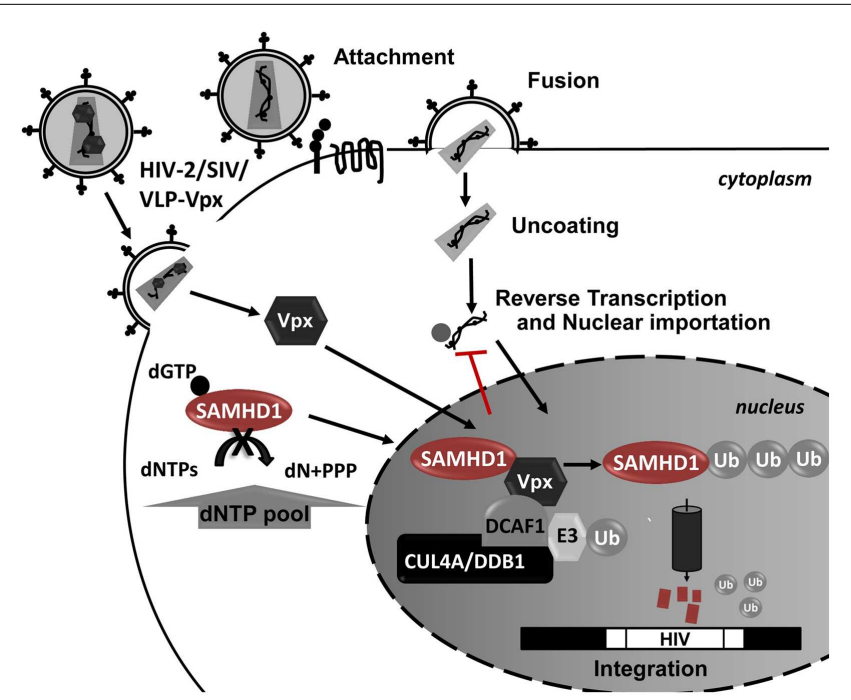

FIGURE 4 | Schematic representation of SAMHD1 Vpx-mediated proteosomal degradation during HIV-1 infection. In the presence of $\mathrm{Vpx}$, SAMHD1 is recruited to a CUL4-DDB1-DCAF1 protein complex in the nucleus, leading to the proteosomal degradation of SAMHD1. The SAMHD1 reduction leads to an increase in the dNTP pool allowing the HIV replication in these cells.
SAMHD1 activity is not correlated with its expression levels, as only resting CD4 T cells restrict HIV-1 infection (288). This observation and the identification of naturally occurring splice variants of SAMHD1 suggest a post-transcriptional regulation of SAMHD1 activity $(288,294)$. SAMHD1 mutations are associated with rare genetic disorders including the Aicardi-Goutieres syndrome (AGS). AGS reproduces a biologic state of viral infection due to excessive production of IFN- $\alpha$ and increased immune activation (295). In addition, monocytes from AGS patients are highly susceptible to HIV-1 infection (285), and mutations that block hydrolase activity result in the loss of SAMHD1 antiviral activity (278). Viral RNA binding to SAMHD1 increases its dNTP hydrolase activity, leading to a rapid elimination of DNA intermediates and the subsequent blockade of HIV-1 replication. Thus, SAMHD1 seems to play a key role in a strategy of the immune system to avoid immune cellular responses upon viral infection.

\section{SAMHD1 CLINICAL STUDIES AND SAMHD1-BASED THERAPEUTICS}

There is evidence that naturally occurring splice variants destabilize SAMHD1 leading to its rapid elimination (294). Such evidence highlights the role of alternative regulatory pathways to control of HIV-1 infection, such as miRNA or post-transcriptional modifications; and the potential relationship between alterations in SAMHD1 activity and disease progression. The therapeutic manipulation of intracellular dNTP pools and the development of SAMHD1 inhibitors to trigger the innate immune response have been suggested as potential anti-retroviral therapies $(281,282)$. However, there is a lack of clinical studies in this direction, and consequently a direct association between SAMHD1 and HIV-1 infection remains to be established. A recent study evaluated the association between SNPs and SAMHD1 expression and activity (296). In this study the authors identified a SAMHD1 SNP, where an A/G substitution occurred at position 59885 (rs1291142), which significantly interfered with the expression of SAMHD1 in B cells from 70 healthy donors. However, they found that this SNP is not present in the genome-wide study of HIV-1 controllers and non-progressors from the larger published European and AfricanAmerican cohorts (296). The authors consequently claim that this SAMHD1 polymorphism probably does not contribute to the control of HIV-1 infection. However, this conclusion is based on their observations of a very small cohort of healthy subjects. LTNPs and HIV controllers are very rare in the general population since most people develop AIDS upon HIV-1 infection. Therefore, in such a small sample it is very unlikely to have a LTNP/controller and, by extension, to identify a SNP in SAMHD1 that could be associated to this phenotype. In summary, the connection between SAMHD1 variants and HIV-1 progression should be further tested in clinical studies. We believe it could provide insight into novel therapeutic strategies against HIV.

\section{CONCLUSION/FINAL REMARKS}

The existence of rare individuals who resist infection, delay the disease outcome or control viral replication without the need of anti-retroviral therapy demonstrates that prevention of infection and long-lasting disease remission are attainable objectives. A 
large group of factors contributes to the balance between viral replication and host antiviral response, including cell-specific RF and "defects" in naturally occurring helper factors.

Despite latest advances in the HIV-1 field, our knowledge on how LTNPs and ECs control HIV-1 infection is still limited. The few genes whose alterations have been found to be correlated with different rates of disease progression cannot fully account for the differences observed among the patients. Thus, the host $\mathrm{RF}$ and genetics responsible for AIDS delay in non-progressors remain to be identified. Here, we reviewed a series of polymorphisms and expression alterations in HIV-helper factors that are related to control of HIV-1 infection, with special focus on those RFs that counteract HIV-1 entrance into and exit from the host cell. Genome-wide genetic association studies confirmed some of the genetic-variants such as CCR5 32 and HLA-B5707 (36) but were not able to pinpoint a single gene common to all LTNPs and responsible for slow disease progression. The choice of very restrictive statistical thresholds or gene chip arrays that do not cover all gene variants or non-coding DNA sequences may exclude relevant host factors from the analysis. However, AIDS is a complex disease and the different rates of disease progression observed may be also due to a combination of multiple factors.

\section{REFERENCES}

1. Deeks SG, Walker BD. Human immunodeficiency virus controllers: mechanisms of durable virus control in the absence of antiretroviral therapy. Immunity (2007) 27:406-16. doi:10.1016/j. immuni.2007.08.010

2. Balotta C, Bagnarelli P, Violin $\mathrm{M}$, Ridolfo AL, Zhou D, Berlusconi A, et al. Homozygous delta 32 deletion of the CCR5 chemokine receptor gene in an HIV-1-infected patient. AIDS (1997) 11:F67-71. doi:10.1097/ 00002030-199710000-00001

3. Hardie RA, Knight E, Bruneau B, Semeniuk C, Gill K, Nagelkerke N, et al. A common human leucocyte antigen-DP genotype is associated with resistance to HIV-1 infection in Kenyan sex workers. AIDS (2008) 22:2038-42. doi:10.1097/QAD.

0b013e328311dla0

4. MacDonald KS, Fowke KR, Kimani J, Dunand VA, Nagelkerke NJ, Ball TB, et al. Influence of HLA supertypes on susceptibility and resistance to human immunodeficiency virus type 1 infection. J Infect Dis (2000) 181:1581-9. doi: 10.1086/315472

5. van $\mathrm{MD}$, van't Wout $\mathrm{AB}$, Schuitemaker H. Genomewide association studies on HIV susceptibility, pathogenesis and pharmacogenomics. Retrovirology (2012) 9:70. doi:10.1186/17424690-9-70
6. Alkhatib G. The biology of CCR5 and CXCR4. Curr Opin HIV AIDS (2009) 4:96-103. doi:10. 1097/COH.0b013e328324bbec

7. Samson M, Labbe O, Mollereau Molecular cloning and functional expression of a new human CCchemokine receptor gene. Biochemistry (1996) 35:3362-7. doi: 10.1021/bi952950g

8. Cocchi F, DeVico AL, GarzinoDemo A, Arya SK, Gallo RC, Lusso P. Identification of RANTES, MIP-1 alpha, and MIP-1 beta as the major HIV-suppressive factors produced by CD8+ T cells. Science (1995) 270:1811-5. doi:10. 1126/science.270.5243.1811

9. Bleul CC, Wu L, Hoxie J, Springer T, Mackay CR. The HIV coreceptors CXCR4 and CCR5 are differentially expressed and regulated on human $\mathrm{T}$ lymphocytes. Proc Natl Acad Sci U S A (1997) 94: 1925-30. doi:10.1073/pnas.94.5. 1925

10. Wu L, Paxton W, Kassam N, Ruffing N, Rottman JB, Sullivan $\mathrm{N}$, et al. CCR5 levels and expression pattern correlate with infectability by macrophage-tropic HIV-1, in vitro. J Exp Med (1997) 185:1681-91. doi:10.1084/ jem.185.9.1681

11. Feng Y, Broder CC, Kennedy PE, Berger EA. HIV-1 entry cofactor: functional cDNA cloning of a seven-transmembrane, G protein-coupled receptor. Science C, Vassart G, Parmentier M.

So far, among all identified genetic factors playing a major role in the HIV decrease, the CCR $5 \Delta 32$ polymorphism remains the main genetic factor conferring human resistance to HIV-1. Display of chemokine receptors at the cell-surface and their conserved structure make them amenable targets for drug development. This is the case for maraviroc and novel gene therapy approaches that are currently used for the treatment of AIDS or are currently being tested in ongoing clinical trials. This example of success in translational research highlights the relevance of a better understanding of how LTNPs control disease progression for the development of new therapeutic tools to cure AIDS. We expect that, in the near future, other drugs or gene-based therapy approaches targeting other host proteins (helper or RFs) will enter clinical trials and translate to the clinic.

\section{ACKNOWLEDGMENTS}

We thank Dr. Federico Herrera, Dr. Lauren Schwimmer, Dr. Antonio Jorge Rodrigues, and Dr. Danial Malamud for help with text editing. Fellowships from Fundação para a Ciência e a Tecnologia, Portugal were awarded to Paula Matos de Brito (SFRH/BPD/39981/2007) and to Ana Godinho-Santos (SFRH/BD/81265/2011).

(1996) 272:872-7. doi:10.1126/ science.272.5263.872

12. Hoffmann C. The epidemiology of HIV coreceptor tropism. Eur JMed Res (2007) 12:385-90.

13. Lusso P. HIV and the chemokine system: 10 years later. $E M B O J$ (2006) 25:447-56. doi:10.1038/sj. emboj.7600947

14. Ma Q, Jones D, Borghesani PR, Segal RA, Nagasawa T, Kishimoto T, et al. Impaired B-lymphopoiesis, myelopoiesis, and derailed cerebellar neuron migration in $\mathrm{C}$. Proc Natl Acad Sci U S A (1998) 95:9448-53. doi:10.1073/pnas.95. 16.9448

15. Cohen OJ, Paolucci S, Bende SM, Daucher M, Moriuchi H, Moriuchi $\mathrm{M}$, et al. CXCR4 and CCR5 genetic polymorphisms in long-term nonprogressive human immunodeficiency virus infection: lack of association with mutations other than CCR5-Delta32. J Virol (1998) 72:6215-7.

16. Pollakis G, Paxton WA. Use of (alternative) coreceptors for HIV entry. Curr Opin HIV AIDS (2012) 7:440-9. doi:10.1097/ COH.0b013e328356e9f3

17. Gorry PR, Zhang C, Wu S, Kunstman K, Trachtenberg E, Phair $\mathrm{J}$, et al. Persistence of dual-tropic HIV-1 in an individual homozygous for the CCR5 delta 32 allele. Lancet (2002) 359:1832-4. doi:10. 1016/S0140-6736(02)08681-6

18. Gray L, Churchill MJ, Keane N, Sterjovski J, Ellett AM, Purcell DF, et al. Genetic and functional analysis of R5X4 human immunodeficiency virus type 1 envelope glycoproteins derived from two individuals homozygous for the CCR5delta32 allele. J Virol (2006) 80:3684-91. doi:10.1128/JVI.80.7. 3684-3691.2006

19. Heiken H, Becker S, Bastisch I, Schmidt RE. HIV-1 infection in a heterosexual man homozygous for CCR-5 delta32. AIDS (1999) 13:529-30. doi:10.1097/ 00002030-199903110-00017

20. Iversen $A K$, Christiansen $C B$, Attermann J, Eugen-Olsen J, Schulman S, Berntorp E, et al. Limited protective effect of the CCR5Delta32/CCR5Delta32 genotype on human immunodeficiency virus infection incidence in a cohort of patients with hemophilia and selection for genotypic X4 virus. J Infect Dis (2003) 187:215-25. doi:10.1086/345881

21. Kuipers H, Workman C, Dyer W, Geczy A, Sullivan J, Oelrichs R. An HIV-1-infected individual homozygous for the CCR-5 delta32 allele and the SDF-1 $3^{\prime} \mathrm{A}$ allele. AIDS (1999) 13:433-4. doi:10.1097/00002030199902250-00025

22. O'Brien TR, Winkler C, Dean M, Nelson JA, Carrington M, Michael NL, et al. HIV-1 infection in a man homozygous for CCR5 delta 32. Lancet (1997) 349:1219. doi:10.1016/S0140-6736(97) 24017-1 
23. Oh DY, Jessen H, Kucherer C, Neumann K, Oh N, Poggensee G, et al. CCR5Delta32 genotypes in a German HIV-1 seroconverter cohort and report of HIV-1 infection in a CCR5Delta32 homozygous individual. PLoS ONE (2008) 3:e2747. doi:10.1371/ journal.pone.0002747

24. Sheppard HW, Celum C, Michael NL, O'Brien S, Dean M, Carrington $\mathrm{M}$, et al. HIV-1 infection in individuals with the CCR5-Delta32/Delta32 genotype: acquisition of syncytiuminducing virus at seroconversion. J Acquir Immune Defic Syndr (2002) 29:307-13. doi:10.1097/ 00126334-200203010-00013

25. Theodorou I, Meyer L, Magierowska M, Katlama C, Rouzioux C. HIV-1 infection in an individual homozygous for CCR5 delta 32. Seroco Study Group. Lancet (1997) 349:1219-20. doi: 10.1016/S0140-6736(05)62411-7

26. Dean M, Carrington M, Winkler C, Huttley GA, Smith MW, Allikmets $\mathrm{R}$, et al. Genetic restriction of HIV-1 infection and progression to AIDS by a deletion allele of the CKR5 structural gene. Science (1996) 273: 1856-62. doi:10.1126/science.273. 5283.1856

27. Eugen-Olsen J, Iversen AK, Garred P, Koppelhus U, Pedersen C, Benfield TL, et al. Heterozygosity for a deletion in the CKR-5 gene leads to prolonged AIDS-free survival and slower CD4 T-cell decline in a cohort of HIV-seropositive individuals. AIDS (1997) 11:305-10. doi:10. 1097/00002030-199703110-00007

28. Huang Y, Paxton WA, Wolinsky SM, Neumann AU, Zhang $\mathrm{L}, \mathrm{He} \mathrm{T}$, et al. The role of a mutant CCR5 allele in HIV-1 transmission and disease progression. Nat Med (1996) 2:1240-3. doi:10.1038/nm1196-1240

29. Zimmerman P, Buckler W, Alkhatib G, Spalding T, Kubofcik J, Combadiere C, et al. Inherited resistance to HIV-1 conferred by an inactivating mutation in CC chemokine receptor 5: studies in populations with contrasting clinical phenotypes, defined racial background, and quantified risk. Mol Med (1997) 3:23-36.

30. Cohen OJ, Vaccarezza M, Lam GK, Baird BF, Wildt K, Murphy PM, et al. Heterozygosity for a defective gene for CC chemokine receptor 5 is not the sole determinant for the immunologic and virologic phenotype of HIV-infected longterm nonprogressors. J Clin Invest (1997) 100:1581-9. doi:10.1172/ JCI119682

31. Schinkel J, Langendam MW, Coutinho RA, Krol A, Brouwer M, Schuitemaker H. No evidence for an effect of the CCR5 delta32/+ and CCR2b 64I/+ mutations on human immunodeficiency virus (HIV)-1 disease progression among HIV-1-infected injecting drug users. J Infect Dis (1999) 179:825-31. doi:10.1086/314658

32. Wilkinson DA, Operskalski EA, Busch MP, Mosley JW, Koup RA. A 32-bp deletion within the CCR5 locus protects against transmission of parenterally acquired human immunodeficiency virus but does not affect progression to AIDSdefining illness. J Infect Dis (1998) 178:1163-6. doi:10.1086/515675

33. Borinskaya SA, Kozhekbaeva Zhm, Zalesov AV, Olseeva EV, Maksimov AR, Kutsev SI, et al. Risk of HIV infection and lethality are decreased in CCR5del32 heterozygotes: focus nosocomial infection study and meta-analysis. Acta Nat (2012) 4:42-52.

34. Ioannidis JP, Rosenberg PS, Goedert JJ, Ashton LJ, Benfield TL, Buchbinder SP, et al. Effects of CCR5-Delta32, CCR2$64 \mathrm{I}$, and SDF-1 $3^{\prime} \mathrm{A}$ alleles on HIV-1 disease progression: an international meta-analysis of individual-patient data. Ann Intern Med (2001) 135:782-95. doi:10.7326/0003-4819-135-9200111060-00008

35. Fellay J, Ge D, Shianna KV, Colombo S, Ledergerber B, Cirulli ET, et al. Common genetic variation and the control of HIV1 in humans. PLoS Genet (2009) 5:e1000791. doi:10.1371/journal. pgen.1000791

36. Pereyra F, Jia X, McLaren PJ, Telenti A, de Bakker PI, Walker BD, et al. The major genetic determinants of HIV-1 control affect HLA class I peptide presentation. Science (2010) 330:1551-7. doi:10. 1126/science.1195271

37. Quillent C, Oberlin E, Braun J, Rousset D, Gonzalez-Canali G, MÃtais P, et al. HIV-1-resistance phenotype conferred by combination of two separate inherited mutations of CCR5 gene. Lancet (1998) 351:14-8. doi:10. 1016/S0140-6736(97)09185-X

38. Clegg AO, Ashton LJ, Biti RA, Badhwar P, Williamson P, Kaldor $\mathrm{JM}$, et al. CCR5 promoter polymorphisms, CCR5 59029A and CCR5 59353C, are under represented in HIV-1-infected long-term non-progressors. the Australian Long-Term NonProgressor Study Group. AIDS (2000) 14:103-8. doi:10.1097/ 00002030-200001280-00004

39. Knudsen TB, Kristiansen TB, Katzenstein TL, Eugen-Olsen J. Adverse effect of the CCR5 promoter-2459A allele on HIV-1 disease progression. J Med Virol (2001) 65:441-4. doi:10.1002/jmv. 2054.abs

40. McDermott DH, Zimmerman P, Guignard F, Kleeberger C, Leitman SF, Murphy PM. CCR5 promoter polymorphism and HIV1 disease progression. Lancet (1998) 352:866-70. doi:10.1016/ S0140-6736(98)04158-0

41. Hladik F, Liu H, Speelmon E, Livingston-Rosanoff D, Wilson $\mathrm{S}$, Sakchalathorn P, et al. Combined effect of CCR5-Delta32 heterozygosity and the CCR5 promoter polymorphism $-2459 \mathrm{~A} / \mathrm{G}$ on CCR5 expression and resistance to human immunodeficiency virus type 1 transmission. J Virol (2005) 79:11677-84. doi:10.1128/JVI.79. 18.11677-11684.2005

42. Salkowitz JR, Bruse SE, Meyerson $\mathrm{H}$, Valdez $\mathrm{H}$, Mosier DE, Harding CV, et al. CCR5 promoter polymorphism determines macrophage CCR5 density and magnitude of HIV-1 propagation in vitro. Clin Immunol (2003) 108:234-40. doi:10.1016/ S1521-6616(03)00147-5

43. Jang DH, Choi BS, Kim SS. The effects of RANTES/CCR5 promoter polymorphisms on HIV disease progression in HIV-infected Koreans. Int J Immunogenet (2008) 35:101-5. doi:10.1111/j.1744-313X.2007. 00743.x

44. Martin MP, Dean M, Smith MW, Winkler C, Gerrard B, Michael NL, et al. Genetic acceleration of AIDS progression by a promoter variant of CCR5. Science (1998) 282:1907-11. doi:10.1126/science. 282.5395.1907

45. Easterbrook PJ, Rostron T, Ives N, Troop M, Gazzard BG, Rowland-Jones SL. Chemokine receptor polymorphisms and human immunodeficiency virus disease progression. $J$ Infect Dis (1999) 180:1096-105. doi:10.1086/314997

46. El-Asmar L, Springael JY, Ballet S, Andrieu EU, Vassart G, Parmentier M. Evidence for negative binding cooperativity within
CCR5-CCR2b heterodimers. Mol Pharmacol (2005) 67:460-9. doi: 10.1124/mol.104.003624

47. Hernanz-Falcon P, RodriguezFrade JM, Serrano A, Juan D, del SA, Soriano SF, et al. Identification of amino acid residues crucial for chemokine receptor dimerization. Nat Immunol (2004) 5:216-23. doi:10.1038/ni1027

48. Issafras $\mathrm{H}$, Angers S, Bulenger S, Blanpain C, Parmentier M, LabbeJullie C, et al. Constitutive agonistindependent CCR5 oligomerization and antibody-mediated clustering occurring at physiological levels of receptors. J Biol Chem (2002) 277:34666-73. doi: 10.1074/jbc.M202386200

49. Mellado M, Rodriguez-Frade JM, Vila-Coro AJ, Fernandez S, Martin de AA, Jones DR, et al. Chemokine receptor homo- or heterodimerization activates distinct signaling pathways. EMBO J (2001) 20:2497-507. doi:10.1093/emboj/ 20.10.2497

50. Sohy D, Parmentier M, Springael JY. Allosteric transinhibition by specific antagonists in CCR2/CXCR4 heterodimers. J Biol Chem (2007) 282:30062-9. doi:10.1074/jbc.M705302200

51. Lee B, Doranz BJ, Rana S, Yi Y, Mellado M, Frade JM, et al. Influence of the CCR2-V64I polymorphism on human immunodeficiency virus type 1 coreceptor activity and on chemokine receptor function of CCR2b, CCR3, CCR5, and CXCR4. J Virol (1998) 72:7450-8.

52. Anzala AO, Ball TB, Rostron T, O'Brien SJ, Plummer FA, Rowland-Jones SL. CCR2-64I allele and genotype association with delayed AIDS progression in African women. University of Nairobi Collaboration for HIV Research. Lancet (1998) 351:1632-3. doi:10.1016/S01406736(05)77688-1

53. Mulherin SA, O'Brien TR, Ioannidis JP, Goedert JJ, Buchbinder SP, Coutinho RA, et al. Effects of CCR5-Delta32 and CCR2-64I alleles on HIV-1 disease progression: the protection varies with duration of infection. AIDS (2003) 17:377-87. doi:10.1097/ 00002030-200302140-00012

54. Puissant BÃ, Roubinet F, Massip P, Sandres-Saune K, Apoil $\mathrm{PA}$, Abbal $\mathrm{M}$, et al. Analysis of CCR5, CCR2, CX3CR1, and SDF1 polymorphisms in HIVpositive treated patients: impact on response to HAART and on peripheral $\mathrm{T}$ lymphocyte counts. 
AIDS Res Hum Retroviruses (2006) 22:153-62. doi:10.1089/aid.2006. 22.153

55. Rizzardi GP, Morawetz RA, Vicenzi E, Ghezzi S, Poli G, Lazzarin A, et al. CCR2 polymorphism and HIV disease. Swiss HIV Cohort. Nat Med (1998) 4:252-3. doi:10.1038/ nm0398-252

56. Smith MW, Dean M, Carrington $\mathrm{M}$, Winkler C, Huttley GA, Lomb DA, et al. Contrasting genetic influence of CCR2 and CCR5 variants on HIV-1 infection and disease progression. Hemophilia Growth and Development Study (HGDS), Multicenter AIDS Cohort Study (MACS), Multicenter Hemophilia Cohort Study (MHCS), San Francisco City Cohort. Science (1997) 277:959-65. doi:10.1126/science.277.5328.959

57. Kostrikis LG, Huang Y, Moore JP, Wolinsky SM, Zhang L, Guo Y, et al. A chemokine receptor CCR2 allele delays HIV-1 disease progression and is associated with a CCR5 promoter mutation. Nat Med (1998) 4:350-3. doi:10.1038/ nm0398-350

58. Suresh P, Wanchu A, Sachdeva RK, Bhatnagar A. Gene polymorphisms in CCR5, CCR2, CX3CR1, SDF-1 and RANTES in exposed but uninfected partners of HIV-1 infected individuals in North India. J Clin Immunol (2006) 26:476-84. doi:10.1007/s10875-006-9036-0

59. Sriwanthana B, Hodge T, Mastro TD, Dezzutti CS, Bond K, Stephens HA, et al. HIV-specific cytotoxic $\mathrm{T}$ lymphocytes, HLAA11, and chemokine-related factors may act synergistically to determine HIV resistance in CCR5 delta32-negative female sex workers in Chiang Rai, Northern Thailand. AIDS Res Hum Retroviruses (2001) 17:719-34. doi:10.1089/ 088922201750236997

60. Louisirirotchanakul S, Liu $H$, Roongpisuthipong A, Nakayama EE, Takebe Y, Shioda $\mathrm{T}$, et al. Genetic analysis of HIV-1 discordant couples in Thailand: association of CCR2 64I homozygosity with HIV-1-negative status. J Acquir Immune Defic Syndr (2002) 29:314-5. doi:10.1097/00126334200203010-00014

61. Nakayama EE, Tanaka Y, Nagai Y, Iwamoto A, Shioda T. A CCR2V64I polymorphism affects stability of CCR2A isoform. AIDS (2004) 18:729-38. doi:10.1097/ 00002030-200403260-00003
62. Berger E, Murphy PM, Farber JM. Chemokine receptors as HIV-1 coreceptors: roles in viral entry, tropism, and disease. Annu Rev Immunol (1999) 17:657-700. doi:10.1146/annurev. immunol.17.1.657

63. O'Brien SJ, Moore JP. The effect of genetic variation in chemokines and their receptors on HIV transmission and progression to AIDS. Immunol Rev (2000) 177:99-111. doi:10.1034/j.1600-065X.2000. 17710.x

64. Rodriguez-Frade JM, del RG, Serrano A, Hernanz-Falcon P, Soriano SF, Vila-Coro AJ, et al. Blocking HIV-1 infection via CCR5 and CXCR4 receptors by acting in trans on the CCR2 chemokine receptor. EMBO J (2004) 23:66-76. doi:10. 1038/sj.emboj.7600020

65. Zhao Q. Dual targeting of CCR2 and CCR5: therapeutic potential for immunologic and cardiovascular diseases. J Leukoc Biol (2010) 88:41-55. doi:10.1189/jlb.1009671

66. Limou S, Coulonges CÃ, Herbeck JT, van Manen D, An P, Le Clerc S, et al. Multiple-cohort genetic association study reveals CXCR6 as a new chemokine receptor involved in long-term nonprogression to AIDS. J Infect Dis (2010) 202:908-15. doi:10.1086/ 655782

67. Duggal P, An P, Beaty TH, Strathdee S, Farzadegan H, Markham RB, et al. Genetic influence of CXCR6 chemokine receptor alleles on PCPmediated AIDS progression among African Americans. Genes Immun (2003) 4:245-50. doi:10.1038/sj.gene.6363950

68. Petit SJ, Chayen NE, Pease JE. Site-directed mutagenesis of the chemokine receptor CXCR6 suggests a novel paradigm for interactions with the ligand CXCL16. Eur J Immunol (2008) 38:2337-50. doi:10.1002/eji. 200838269

69. Passam AM, Sourvinos G, Krambovitis E, Miyakis S, Stavrianeas $\mathrm{N}$, Zagoreos I, et al. Polymorphisms of $\mathrm{Cx}(3) \mathrm{CR} 1$ and CXCR6 receptors in relation to HAART therapy of HIV type 1 patients. AIDS Res Hum Retroviruses (2007) 23:1026-32. doi:10.1089/aid.2006. 0248

70. Faure S, Meyer L, Costagliola D, Vaneensberghe C, Genin E, Autran B, et al. Rapid progression to AIDS in HIV+ individuals with a structural variant of the chemokine receptor CX3CR1.
Science (2000) 287:2274-7. doi:10. 1126/science.287.5461.2274

71. Haas G, Samri A, Gomard E, Hosmalin A, Duntze J, Bouley JM, et al. Cytotoxic T-cell responses to HIV-1 reverse transcriptase, integrase and protease. AIDS (1998) 12:1427-36. doi:10.1097/ 00002030-199812000-00004

72. Magierowska M, Theodorou I, DebrÃ P, Sanson F, Autran B, Rivi Ã Y, et al. Combined genotypes of CCR5, CCR2, SDF1, and HLA genes can predict the long-term nonprogressor status in human immunodeficiency virus-1-infected individuals. Blood (1999) 93:936-41

73. Meyer L, Magierowska M, Hubert JB, Rouzioux C, Deveau C, Sanson $\mathrm{F}$, et al. Early protective effect of CCR-5 delta 32 heterozygosity on HIV-1 disease progression: relationship with viral load. The SEROCO Study Group. AIDS (1997) 11:F73-8.

74. McDermott DH. Genetic polymorphism in CX3CR1 and risk of HIV disease. Science (2000) 290:2031a-22031a. doi:10.1126/ science.290.5499.2031a

75. Hendel H, Cho YY, Gauthier N, Rappaport J, Schachter F, Zagury JF. Contribution of cohort studies in understanding HIV pathogenesis: introduction of the GRIV cohort and preliminary results. Biomed Pharmacother (1996) 50:480-7. doi:10.1016/S07533322(97)89278-5

76. Vidal F, ViladÃ C, Domingo P, Broch M, Pedrol E, Dalmau $\mathrm{D}$, et al. Spanish HIV-1-infected long-term nonprogressors of more than 15 years have an increased frequency of the CX3CR1 249I variant allele. J Acquir Immune Defic Syndr (2005) 40:527-31. doi:10.1097/01.qai.0000186362. 50457.e0

77. Modi WS, Lautenberger J, An P, Scott K, Goedert JJ, Kirk GD, et al. Genetic variation in the CCL18CCL3-CCL4 chemokine gene cluster influences HIV Type 1 transmission and AIDS disease progression. Am J Hum Genet (2006) 79:120-8. doi:10.1086/505331

78. Blanpain C, Migeotte I, Lee B, Vakili J, Doranz BJ, Govaerts C, et al. CCR5 binds multiple CCchemokines: MCP-3 acts as a natural antagonist. Blood (1999) 94:1899-905.

79. Piacentini L, Biasin M, Fenizia C, Clerici M. Genetic correlates of protection against HIV infection: the ally within. J Intern Med
(2009) 265:110-24. doi:10.1111/j. 1365-2796.2008.02041.x

80. Saha K, Bentsman G, Chess L, David J. Endogenous production of $\hat{\mathrm{l}}^{2}$-chemokines by CD $4+$, but Not CD8 +, t-cell clones correlates with the clinical state of human immunodeficiency virus type 1 (HIV-1)-infected individuals and may be responsible for blocking infection with nonsyncytiuminduc. J Virol (1998) 72:876-81.

81. Nakajima T, Kaur G, Mehra N, Kimura A. HIV-1/AIDS susceptibility and copy number variation in CCL3L1, a gene encoding a natural ligand for HIV-1 coreceptor CCR5. Cytogenet Genome Res (2008) 123:156-60. doi:10. 1159/000184703

82. Gonzalez E, Kulkarni H, Bolivar H, Mangano A, Sanchez R, Catano $\mathrm{G}$, et al. The influence of CCL3L1 gene-containing segmental duplications on HIV-1/AIDS susceptibility. Science (2005) 307:1434-40. doi: $10.1126 /$ science. 1101160

83. Liu S, Yao L, Ding D, Zhu $\mathrm{H}$. CCL3L1 copy number variation and susceptibility to HIV-1 infection: a meta-analysis. PLOS ONE (2010) 5:e15778. doi:10.1371/ journal.pone.0015778

84. Rathore A, Chatterjee A, Sivarama P, Yamamoto N, Singhal PK, Dhole TN. Association of CCR559029 A/G and CCL3L1 copy number polymorphism with HIV type 1 transmission/progression among HIV type 1-seropositive and repeatedly sexually exposed HIV type 1-seronegative North Indians. AIDS Res Hum Retroviruses (2009) 25:1149-56. doi:10. 1089/aid.2008.0019

85. Gaertner H, Cerini F, Escola JM, Kuenzi G, Melotti A, Offord R, et al. Highly potent, fully recombinant anti-HIV chemokines: reengineering a low-cost microbicide. Proc Natl Acad Sci U S A (2008) 105:17706-11. doi:10.1073/pnas. 0805098105

86. Hartley O, Gaertner H, Wilken J, Thompson D, Fish R, Ramos A, et al. Medicinal chemistry applied to a synthetic protein: development of highly potent HIV entry inhibitors. Proc Natl Acad Sci US A (2004) 101:16460-5. doi:10.1073/ pnas.0404802101

87. Toossi Z, Mayanja-Kizza H, Baseke J, Peters P, Wu M, Abraha $A$, et al. Inhibition of human immunodeficiency virus-1 (HIV1) by beta-chemokine analogues in mononuclear cells from HIV1-infected patients with active 
tuberculosis. Clin Exp Immunol (2005) 142:327-32. doi:10.1111/j. 1365-2249.2005.02913.x

88. Lederman MM, Veazey RS, Offord R, Mosier DE, Dufour J, Mefford $\mathrm{M}$, et al. Prevention of vaginal SHIV transmission in rhesus macaques through inhibition of CCR5. Science (2004) 306:485-7. doi:10.1126/science.1099288

89. Veazey RS, Ling B, Green LC, Ribka EP, Lifson JD, Piatak M Jr., et al. Topically applied recombinant chemokine analogues fully protect macaques from vaginal simian-human immunodeficiency virus challenge. J Infect Dis (2009) 199:1525-7. doi:10.1086/598685

90. Liu H, Chao D, Nakayama EE, Taguchi H, Goto M, Xin X, et al. Polymorphism in RANTES chemokine promoter affects HIV-1 disease progression. Proc Natl Acad Sci U S A (1999) 96: 4581-5. doi:10.1073/pnas.96.8. 4581

91. McDermott DH, Beecroft MJ, Kleeberger CA, Al-Sharif FM, Ollier WE, Zimmerman PA, et al. Chemokine RANTES promoter polymorphism affects risk of both HIV infection and disease progression in the multicenter AIDS Cohort Study. AIDS (2000) 14:2671-8. doi:10.1097/ 00002030-200012010-00006

92. Vidal F, Peraire J, Domingo P, Broch M, Cairo M, Pedrol E, et al. Polymorphism of RANTES chemokine gene promoter is not associated with long-term nonprogressive HIV-1 infection of more than 16 years. J Acquir Immune Defic Syndr (2006) 41:17-22. doi:10.1097/01.qai. 0000188335.86466.ea

93. An P, Nelson GW, Wang L, Donfield S, Goedert JJ, Phair J, et al. Modulating influence on HIV/AIDS by interacting RANTES gene variants. Proc Natl Acad Sci U S A (2002) 99:10002-7. doi:10. 1073/pnas.142313799

94. Bleul CC, Farzan M, Choe H, Parolin C, Clark-Lewis I, Sodroski J, et al. The lymphocyte chemoattractant SDF-1 is a ligand for LESTR/fusin and blocks HIV-1 entry. Nature (1996) 382:829-33. doi:10.1038/382829a0

95. Oberlin E, Amara A, Bachelerie F, Bessia C, Virelizier JL, ArenzanaSeisdedos F, et al. The CXC chemokine SDF-1 is the ligand for LESTR/fusin and prevents infection by T-cell-line-adapted HIV-1. Nature (1996) 382:833-5. doi:10. $1038 / 382833 \mathrm{a} 0$
96. Amara A, Gall SL, Schwartz O, Salamero J, Montes M, Loetscher $\mathrm{P}$, et al. HIV coreceptor downregulation as antiviral principle: SDF1alpha-dependent internalization of the chemokine receptor CXCR4 contributes to inhibition of HIV replication. J Exp Med (1997) 186:139-46. doi:10.1084/jem.186. 1.139

97. Signoret N, Oldridge J, PelchenMatthews A, Klasse PJ, Tran T, Brass LF, et al. Phorbol esters and SDF-1 induce rapid endocytosis and down modulation of the chemokine receptor CXCR4. J Cell Biol (1997) 139:651-64. doi: 10.1083/jcb.139.3.651

98. Hendel H, Henon N, Lebuanec H, Lachgar A, Poncelet H, CaillatZucman S, et al. Distinctive effects of CCR5, CCR2, and SDF1 genetic polymorphisms in AIDS progression. J Acquir Immune Defic Syndr Hum Retrovirol (1998) 19:381-6. doi:10.1097/00042560199812010-00009

99. Mahajan SD, Agosto-Mojica A, Aalinkeel R, Reynolds JL, Nair BB, Sykes DE, et al. Role of chemokine and cytokine polymorphisms in the progression of HIV-1 disease. Biochem Biophys Res Commun (2010) 396:348-52. doi:10. 1016/j.bbrc.2010.04.095

100. Winkler C, Modi W, Smith MW, Nelson GW, Wu X, Carrington $\mathrm{M}$, et al. Genetic restriction of AIDS pathogenesis by an SDF-1 chemokine gene variant. ALIVE Study, Hemophilia Growth and Development Study (HGDS), Multicenter AIDS Cohort Study (MACS), Multicenter Hemophilia Cohort Study (MHCS), San Francisco City Cohort (SFCC). Science (1998) 279:389-93. doi:10.1126/ science.279.5349.389

101. Soriano A, Martínez C, García F Plana M, Palou E, Lejeune MN, et al. Plasma stromal cell-derived factor (SDF)-1 levels, SDF1-3'A genotype, and expression of CXCR4 on $\mathrm{T}$ lymphocytes: their impact on resistance to human immunodeficiency virus type 1 infection and its progression. J Infect Dis (2002) 186:922-31. doi:10.1086/343741

102. van Rij RP, Broersen S, Goudsmit J, Coutinho RA, Schuitemaker H. The role of a stromal cellderived factor-1 chemokine gene variant in the clinical course of HIV-1 infection. AIDS (1998) 12:F85-90. doi:10.1097/ 00002030-199809000-00002

103. Vidal F, Peraire J, Domingo P, Broch M, Knobel H, Pedrol E, et al. Lack of association of SDF$13^{\prime}$ A variant allele with longterm nonprogressive HIV-1 infection is extended beyond 16 years. J Acquir Immune Defic Syndr (2005) 40:276-9. doi:10.1097/01. qai.0000176653.89769.4d

104. Wang FS, Hong WG, Cao Y, Liu MX, Jin L, Hu LP, et al. Population survey of CCR5 delta32, CCR5 $\mathrm{m} 303$, CCR $2 \mathrm{~b}$ 64I, and SDF1 $3^{\prime} \mathrm{A}$ allele frequencies in indigenous Chinese healthy individuals, and in HIV-1-infected and HIV1-uninfected individuals in HIV-1 risk groups. J Acquir Immune Defic Syndr (2003) 32:124-30. doi:10. 1097/00126334-200302010-00002

105. Nichols WG, Steel HM, Bonny T, Adkison K, Curtis L, Millard J, et al. Hepatotoxicity observed in clinical trials of aplaviroc (GW873140). Antimicrob Agents Chemother (2008) 52:858-65. doi: 10.1128/AAC.00821-07

106. Caseiro MM, Nelson M, Diaz RS, Gathe J, de Andrade Neto JL, Slim J, et al. Vicriviroc plus optimized background therapy for treatment-experienced subjects with CCR5 HIV-1 infection: final results of two randomized phase III trials. J Infect (2012) 65:326-35. doi:10.1016/j.jinf.2012.05.008

107. Klibanov OM, Williams SH, Iler CA. Cenicriviroc, an orally active CCR5 antagonist for the potential treatment of HIV infection. Curr Opin Investig Drugs (2010) 11:940-50.

108. Lalezari J, Gathe J, Brinson C, Thompson M, Cohen C, Dejesus E, et al. Safety, efficacy, and pharmacokinetics of TBR-652, a CCR5/CCR2 antagonist, in HIV1-infected, treatment-experienced, CCR5 antagonist-naive subjects. J Acquir Immune Defic Syndr (2011) 57:118-25. doi:10.1097/ QAI.0b013e318213c2c0

109. Marier JF, Pheng L, Trinh MM, Burris HA III, Jones S, Anderson $\mathrm{K}$, et al. Pharmacokinetics of SN2310, an injectable emulsion that incorporates a new derivative of SN-38 in patients with advanced solid tumors. JPharm Sci (2011) 100:4536-45. doi:10.1002/ jps. 22645

110. Jacobson JM, Lalezari JP, Thompson MA, Fichtenbaum CJ, Saag MS, Zingman BS, et al. Phase 2a study of the CCR5 monoclonal antibody PRO 140 administered intravenously to HIVinfected adults. Antimicrob Agents Chemother (2010) 54:4137-42. doi:10.1128/AAC.00086- 10
111. Alkhatib G, Locati M, Kennedy PE, Murphy PM, Berger EA. HIV-1 coreceptor activity of CCR5 and its inhibition by chemokines: independence from $G$ protein signaling and importance of coreceptor downmodulation. Virology (1997) 234:340-8. doi:10.1006/viro.1997. 8673

112. Dorr P, Westby M, Dobbs S, Griffin P, Irvine B, Macartney M, et al. Maraviroc (UK-427,857), a potent, orally bioavailable, and selective small-molecule inhibitor of chemokine receptor CCR5 with broad-spectrum anti-human immunodeficiency virus type 1 activity. Antimicrob Agents Chemother (2005) 49:4721-32. doi:10.1128/AAC.49.11.47214732.2005

113. Jacobson JM, Thompson MA, Lalezari JP, Saag MS, Zingman BS, D'Ambrosio P, et al. Anti-HIV1 activity of weekly or biweekly treatment with subcutaneous PRO 140, a CCR5 monoclonal antibody. J Infect Dis (2010) 201:1481-7. doi: $10.1086 / 652190$

114. DiGiusto DL, Krishnan A, Li L, $\mathrm{Li}$ H. RNA-based gene therapy for HIV with lentiviral vectormodified CD34 $(+)$ cells in patients undergoing transplantation for AIDS-related lymphoma. Science Transl Med (2010) 2:doi:10.1126/ scitranslmed.3000931

115. Kim SS, Peer D, Kumar P, Subramanya S, Wu H, Asthana D, et al. RNAi-mediated CCR5 silencing by LFA-1-targeted nanoparticles prevents HIV infection in BLT mice. Mol Ther (2010) 18:370-6. doi:10. 1038/mt.2009.271

116. Perez EE, Wang J, Miller JC, Jouvenot Y, Kim KA, Liu O, et al. Establishment of HIV-1 resistance in CD4+ $\mathrm{T}$ cells by genome editing using zinc-finger nucleases. Nat Biotechnol (2008) 26:808-16. doi: $10.1038 /$ nbt1410

117. Swan CH, Buhler B, Steinberger P, Tschan MP, Barbas CF III, Torbett BE. T-cell protection and enrichment through lentiviral CCR5 intrabody gene delivery. Gene Ther (2006) 13:1480-92. doi:10.1038/sj. gt.3302801

118. Allers K, Hutter G, Hofmann J, Loddenkemper C, Rieger K, Thiel E, et al. Evidence for the cure of HIV infection by CCR5Delta32/Delta32 stem cell transplantation. Blood (2011) 117:2791-9. doi:10.1182/blood2010-09-309591

119. Hutter G, Nowak D, Mossner M, Ganepola S, Mussig A, Allers 
$\mathrm{K}$, et al. Long-term control of HIV by CCR5 Delta32/Delta32 stem-cell transplantation. $N$ Engl J Med (2009) 360:692-8. doi:10. 1056/NEJMoa0802905

120. Shimizu S, Hong P, Arumugam B, Pokomo L, Boyer J, Koizumi $\mathrm{N}$, et al. A highly efficient short hairpin RNA potently downregulates CCR5 expression in systemic lymphoid organs in the huBLT mouse model. Blood (2010) 115:1534-44. doi:10.1182/blood2009-04-215855

121. Carroll D. Genome engineering with zinc-finger nucleases. Genetics (2011) 188:773-82. doi:10. 1534/genetics.111.131433

122. Holt N, Wang J, Kim K, Friedman G, Wang X, Taupin V, et al. Human hematopoietic stem/progenitor cells modified by zinc-finger nucleases targeted to CCR5 control HIV-1 in vivo. Nat Biotechnol (2010) 28:839-47. doi:10.1038/nbt.1663

123. Conticello SG. The AID/APOBEC family of nucleic acid mutators. Genome Biol (2008) 9:229. doi:10. 1186/gb-2008-9-6-229

124. Pham P, Bransteitter R, Goodman MF. Reward versus risk: DNA cytidine deaminases triggering immunity and disease. Biochemistry (2005) 44:2703-15. doi: 10.1021/bi047481+

125. Chiu YL, Soros VB, Kreisberg JF, Stopak K, Yonemoto W, Greene WC. Cellular APOBEC3G restricts HIV-1 infection in resting CD4+ T cells. Nature (2005) 435:108-14. doi:10.1038/nature03493

126. Pion M, Granelli-Piperno A, Mangeat B, Stalder R, Correa $\mathrm{R}$, Steinman $\mathrm{RM}$, et al. APOBEC3G/3F mediates intrinsic resistance of monocyte-derived dendritic cells to HIV-1 infection. J Exp Med (2006) 203:2887-93. doi:10.1084/jem.20061519

127. Stopak KS, Chiu YL, Kropp J, Grant RM, Greene WC. Distinct patterns of cytokine regulation of APOBEC3G expression and activity in primary lymphocytes, macrophages, and dendritic cells. J Biol Chem (2007) 282:3539-46. doi:10.1074/jbc.M610138200

128. Chiu YL, Greene WC. APOBEC3G: an intracellular centurion. Philos Trans $R$ Soc Lond B Biol Sci (2009) 364:689-703. doi:10.1098/ rstb.2008.0193

129. Smith HC, Bennett RP, Kizilyer A, McDougall WM, Prohaska KM. Functions and regulation of the APOBEC family of proteins. Semin Cell Dev Biol (2012) 23:
258-68. doi:10.1016/j.semcdb. 2011.10.004

130. Mariani R, Chen D, Schrofelbauer B, Navarro F, Konig R, Bollman B, et al. Species-specific exclusion of APOBEC3G from HIV-1 virions by Vif. Cell (2003) 114:21-31. doi:10.1016/S00928674(03)00515-4

131. Stopak K, de Noronha C, Yonemoto W, Greene WC. HIV-1 Vif blocks the antiviral activity of APOBEC3G by impairing both its translation and intracellular stability. Mol Cell (2003) 12:591-601. doi:10.1016/S10972765(03)00353-8

132. Chiu YL, Witkowska HE, Hall SC, Santiago M, Soros VB, Esnault $\mathrm{C}$, et al. High-molecular-mass APOBEC3G complexes restrict Alu retrotransposition. Proc Natl Acad Sci U S A (2006) 103:15588-93. doi:10.1073/pnas.0604524103

133. Kreisberg JF, Yonemoto W, Greene WC. Endogenous factors enhance HIV infection of tissue naive CD4 $\mathrm{T}$ cells by stimulating high molecular mass APOBEC3G complex formation. J Exp Med (2006) 203:865-70. doi:10.1084/ jem.20051856

134. Suspene R, Sommer P, Henry M, Ferris S, Guetard D, Pochet S, et al. APOBEC3G is a singlestranded DNA cytidine deaminase and functions independently of HIV reverse transcriptase. Nucleic Acids Res (2004) 32:2421-9. doi: 10.1093/nar/gkh554

135. Yu Q, Konig R, Pillai S, Chiles K, Kearney M, Palmer S, et al. Singlestrand specificity of APOBEC $3 \mathrm{G}$ accounts for minus-strand deamination of the HIV genome. Nat Struct Mol Biol (2004) 11:435-42. doi:10.1038/nsmb758

136. Schrofelbauer B, Yu Q, Zeitlin SG, Landau NR. Human immunodeficiency virus type $1 \mathrm{Vpr}$ induces the degradation of the UNG and SMUG uracil-DNA glycosylases. J Virol (2005) 79:10978-87. doi:10. 1128/JVI.79.17.10978-10987.2005

137. Yang B, Chen K, Zhang C, Huang S, Zhang H. Virion-associated uracil DNA glycosylase-2 and apurinic/apyrimidinic endonuclease are involved in the degradation of APOBEC3G-edited nascent HIV-1 DNA. J Biol Chem (2007) 282:11667-75. doi:10.1074/jbc.M606864200

138. Harris RS, Bishop KN, Sheehy AM, Craig HM, Petersen-Mahrt SK, Watt IN, et al. DNA deamination mediates innate immunity to retroviral infection. Cell
(2003) 113:803-9. doi:10.1016/ S0092-8674(03)00423-9

139. Lecossier D, Bouchonnet F, Clavel F, Hance AJ. Hypermutation of HIV-1 DNA in the absence of the Vif protein. Science (2003) 300:1112. doi:10.1126/science. 1083338

140. Mangeat B, Turelli P, Caron G, Friedli M, Perrin L, Trono D. Broad antiretroviral defence by human APOBEC3G through lethal editing of nascent reverse transcripts. Nature (2003) 424:99-103. doi:10. 1038/nature01709

141. Zhang $H$, Yang B, Pomerantz RJ, Zhang C, Arunachalam SC, Gao L. The cytidine deaminase CEM15 induces hypermutation in newly synthesized HIV-1 DNA. Nature (2003) 424:94-8. doi:10. 1038/nature01707

142. Newman EN, Holmes RK, Craig HM, Klein KC, Lingappa JR, Malim $\mathrm{MH}$, et al. Antiviral function of APOBEC3G can be dissociated from cytidine deaminase activity. Curr Biol (2005) 15:166-70. doi:10.1016/j.cub.2004.12.068

143. Shindo K, Takaori-Kondo A, Kobayashi M, Abudu A, Fukunaga K, Uchiyama T. The enzymatic activity of CEM15/Apobec-3G is essential for the regulation of the infectivity of HIV-1 virion but not a sole determinant of its antiviral activity. $J$ Biol Chem (2003) 278:44412-6. doi:10.1074/jbc.C300376200

144. Mbisa JL, Barr R, Thomas JA, Vandegraaff $\mathrm{N}$, Dorweiler IJ, Svarovskaia ES, et al. Human immunodeficiency virus type 1 cDNAs produced in the presence of APOBEC3G exhibit defects in plus-strand DNA transfer and integration. J Virol (2007) 81:7099-110. doi:10.1128/JVI.00272-07

145. Bishop KN, Verma M, Kim EY, Wolinsky SM, Malim MH. APOBEC3G inhibits elongation of HIV-1 reverse transcripts. PLoS Pathog (2008) 4:e1000231. doi:10. 1371/journal.ppat.1000231

146. Guo F, Cen S, Niu M, Saadatmand J, Kleiman L. Inhibition of formula-primed reverse transcription by human APOBEC3G during human immunodeficiency virus type 1 replication. J Virol (2006) 80:11710-22. doi:10.1128/ JVI.01038-06

147. Han Y, Wang X, Dang Y, Zheng YH. APOBEC3G and APOBEC3F require an endogenous cofactor to block HIV-1 replication. PLoS
Pathog (2008) 4:e1000095. doi:10. 1371/journal.ppat.1000095

148. Anderson JL, Hope TJ. APOBEC3G restricts early HIV-1 replication in the cytoplasm of target cells. Virology (2008) 375:1-12. doi:10.1016/j.virol. 2008.01.042

149. Luo K, Wang T, Liu B, Tian C, Xiao Z, Kappes J, et al. Cytidine deaminases APOBEC3G and APOBEC3F interact with human immunodeficiency virus type 1 integrase and inhibit proviral DNA formation. J Virol (2007) 81:7238-48. doi:10. 1128/JVI.02584-06

150. Mbisa JL, Bu W, Pathak VK. APOBEC3F and APOBEC3G inhibit HIV-1 DNA integration by different mechanisms. J Virol (2010) 84:5250-9. doi:10.1128/JVI.02358-09

151. Holmes RK, Koning FA, Bishop $\mathrm{KN}$, Malim MH. APOBEC3F can inhibit the accumulation of HIV1 reverse transcription products in the absence of hypermutation. Comparisons with APOBEC3G. J Biol Chem (2007) 282:2587-95. doi:10.1074/jbc.M607298200

152. Yang Y, Guo F, Cen S, Kleiman L. Inhibition of initiation of reverse transcription in $\mathrm{HIV}-1$ by human APOBEC3F. Virology (2007) 365:92-100. doi:10.1016/j. virol.2007.03.022

153. Goila-Gaur R, Strebel K. HIV-1 Vif, APOBEC, and intrinsic immunity. Retrovirology (2008) 5:51. doi:10. 1186/1742-4690-5-51

154. Harris RS, Liddament MT. Retroviral restriction by APOBEC proteins. Nat Rev Immunol (2004) 4:868-77. doi:10.1038/nri1489

155. Sheehy AM, Gaddis NC, Choi JD, Malim MH. Isolation of a human gene that inhibits HIV1 infection and is suppressed by the viral Vif protein. Nature (2002) 418:646-50. doi:10.1038/ nature00939

156. Conticello SG, Harris RS, Neuberger MS. The Vif protein of HIV triggers degradation of the human antiretroviral DNA deaminase APOBEC3G. Curr Biol (2003) 13:2009-13. doi:10.1016/j. cub.2003.10.034

157. Marin M, Rose KM, Kozak SL, Kabat D. HIV-1 Vif protein binds the editing enzyme APOBEC3G and induces its degradation. Nat Med (2003) 9:1398-403. doi:10. 1038/nm946

158. Mehle A, Goncalves J, Santa-Marta M, McPike M, Gabuzda D. Phosphorylation of a novel SOCSbox regulates assembly of the 
HIV-1 Vif-Cul5 complex that promotes APOBEC3G degradation. Genes Dev (2004) 18:2861-6. doi: 10.1101/gad.1249904

159. Mehle A, Strack B, Ancuta P, Zhang C, McPike M, Gabuzda D. Vif overcomes the innate antiviral activity of APOBEC3G by promoting its degradation in the ubiquitinproteasome pathway. J Biol Chem (2004) 279:7792-8. doi:10.1074/ jbc.M313093200

160. Yu X, Yu Y, Liu B, Luo K, Kong $\mathrm{W}$, Mao $\mathrm{P}$, et al. Induction of APOBEC3G ubiquitination and degradation by an HIV-1 VifCul5-SCF complex. Science (2003) 302:1056-60. doi:10.1126/science. 1089591

161. Yu Y, Xiao Z, Ehrlich ES, Yu $X$, Yu XF. Selective assembly of HIV-1 Vif-Cul5-ElonginBElonginC E3 ubiquitin ligase complex through a novel SOCS box and upstream cysteines. Genes Dev (2004) 18:2867-72. doi:10.1101/gad.1250204

162. Du J, Zhao K, Rui Y, Li P, Zhou $X$, Zhang W, et al. Differential Requirements for HIV-1 Vifmediated APOBEC3G degradation and RUNX1-mediated transcription by core binding factor beta. J Virol (2013) 87:1906-11. doi:10.1128/JVI.02199-12

163. Jager S, Kim DY, Hultquist JF, Shindo K, LaRue RS, Kwon E, et al. Vif hijacks CBF-beta to degrade APOBEC3G and promote HIV-1 infection. Nature (2012) 481:371-5. doi:10.1038/ nature 10693

164. Kim DY, Kwon E, Hartley PD, Crosby DC, Mann S, Krogan NJ, et al. CBFbeta stabilizes HIV Vif to counteract APOBEC3 at the expense of RUNX1 target gene expression. Mol Cell (2013) 49:632-44. doi:10.1016/j. molcel.2012.12.012

165. Zhang W, Du J, Evans SL, Yu Y, Yu XF. T-cell differentiation factor CBF-beta regulates HIV-1 Vifmediated evasion of host restriction. Nature (2012) 481:376-9. doi:10.1038/nature10718

166. Cen S, Guo F, Niu M, Saadatmand J, Deflassieux J, Kleiman L. The interaction between HIV$1 \mathrm{Gag}$ and APOBEC3G. J Biol Chem (2004) 279:33177-84. doi: 10.1074/jbc.M402062200

167. Opi S, Kao S, Goila-Gaur R, Khan MA, Miyagi E, Takeuchi H, et al. Human immunodeficiency virus type 1 Vif inhibits packaging and antiviral activity of a degradationresistant APOBEC3G variant. $J$
Virol (2007) 81:8236-46. doi:10. 1128/JVI.02694-06

168. Syed F, McCrae MA. Interactions in vivo between the Vif protein of HIV-1 and the precursor [Pr55(GAG)] of the virion nucleocapsid proteins. Arch Virol (2009) 154:1797-805. doi:10. 1007/s00705-009-0520-8

169. Santa-Marta M, da Silva FA, Fonseca AM, Goncalves J. HIV-1 Vif can directly inhibit apolipoprotein B mRNA-editing enzyme catalytic polypeptide-like 3G-mediated cytidine deamination by using a single amino acid interaction and without protein degradation. $J$ Biol Chem (2005) 280:8765-75. doi:10.1074/jbc.M409309200

170. Huang Y, Zhang L, Ho DD. Characterization of gag and pol sequences from long-term survivors of human immunodeficiency virus type 1 infection. Virology (1998) 240:36-49. doi:10. 1006/viro.1997.8913

171. Janini M, Rogers M, Birx DR, McCutchan FE. Human immunodeficiency virus type 1 DNA sequences genetically damaged by hypermutation are often abundant in patient peripheral blood mononuclear cells and may be generated during near-simultaneous infection and activation of $\mathrm{CD} 4(+) \mathrm{T}$ cells. $J$ Virol (2001) 75:7973-86. doi:10. 1128/JVI.75.17.7973-7986.2001

172. Kao S, Miyagi E, Khan MA, Takeuchi H, Opi S, Goila-Gaur $\mathrm{R}$, et al. Production of infectious human immunodeficiency virus type 1 does not require depletion of APOBEC3G from virus-producing cells. Retrovirology (2004) 1:27. doi:10.1186/ 1742-4690-1-27

173. Kieffer TL, Kwon P, Nettles RE, Han Y, Ray SC, Siliciano RF. G $>\mathrm{A}$ hypermutation in protease and reverse transcriptase regions of human immunodeficiency virus type 1 residing in resting $\mathrm{CD} 4+$ $\mathrm{T}$ cells in vivo. $J$ Virol (2005) 79:1975-80. doi:10.1128/JVI.79.3. 1975-1980.2005

174. Pace C, Keller J, Nolan D, James I, Gaudieri S, Moore C, et al. Population level analysis of human immunodeficiency virus type 1 hypermutation and its relationship with APOBEC3G and vif genetic variation. J Virol (2006) 80:9259-69. doi:10.1128/ JVI.00888-06

175. Vetter ML, Johnson ME, Antons AK, Unutmaz D, D'Aquila RT. Differences in APOBEC3G expression in CD4+ Thelper lymphocyte subtypes modulate HIV-1 infectivity. PLoS Pathog (2009) 5:e1000292. doi:10.1371/journal.ppat.1000292

176. Smith HC. APOBEC3G: a double agent in defense. Trends Biochem Sci (2011) 36:239-44. doi:10.1016/ j.tibs.2010.12.003

177. Simon V, Zennou V, Murray D, Huang Y, Ho DD, Bieniasz PD. Natural variation in Vif: differential impact on APOBEC $3 \mathrm{G} / 3 \mathrm{~F}$ and a potential role in HIV-1 diversification. PLoS Pathog (2005) 1:e6 doi:10.1371/journal.ppat.0010006

178. An P, Bleiber G, Duggal P, Nelson $G$, May $M$, Mangeat $B$, et al. APOBEC3G genetic variants and their influence on the progression to AIDS. J Virol (2004) 78:11070-6. doi:10.1128/ JVI.78.20.11070-11076.2004

179. Jin X, Brooks A, Chen H, Bennett R, Reichman R, Smith $\mathrm{H}$. APOBEC3G/CEM15 (hA3G) mRNA levels associate inversely with human immunodeficiency virus viremia. J Virol (2005) 79:11513-6. doi:10.1128/JVI.79. 17.11513-11516.2005

180. Jin X, Wu H, Smith H. APOBEC3G levels predict rates of progression to AIDS. Retrovirology (2007) 4:20. doi:10.1186/1742-4690-4-20

181. Reddy K, Winkler CA, Werner L, Mlisana K, Abdool Karim SS, Ndung'u T. APOBEC3G expression is dysregulated in primary HIV-1 infection and polymorphic variants influence CD4+ T-cell counts and plasma viral load. AIDS (2010) 24:195-204. doi:10.1097/ QAD.0b013e3283353bba

182. Vazquez-Perez JA, Ormsby CE, Hernandez-Juan R, Torres KJ, Reyes-Teran G. APOBEC3G mRNA expression in exposed seronegative and early stage HIV infected individuals decreases with removal of exposure and with disease progression. Retrovirology (2009) 6:23. doi:10.1186/1742-4690-6-23

183. Do H, Vasilescu A, Diop G, Hirtzig T, Heath SC, Coulonges C, et al. Exhaustive genotyping of the CEM15 (APOBEC3G) gene and absence of association with AIDS progression in a French cohort. $J$ Infect Dis (2005) 191:159-63. doi: $10.1086 / 426826$

184. Cho SJ, Drechsler H, Burke RC, Arens MQ, Powderly W, Davidson NO. APOBEC3F and APOBEC3G mRNA levels do not correlate with human immunodeficiency virus type 1 plasma viremia or CD4+ T-cell count. J Virol (2006)
80:2069-72. doi:10.1128/JVI.80.4. 2069-2072.2006

185. Ulenga NK, Sarr AD, ThakoreMeloni S, Sankale JL, Eisen G, Kanki PJ. Relationship between human immunodeficiency type 1 infection and expression of human APOBEC3G and APOBEC3F. Infect Dis (2008) 198:486-92. doi: 10.1086/590212

186. Zhao M, Geng W, Jiang $Y$, Han X, Cui H, Dai D, et al. The associations of hA3G and hA3B mRNA levels with HIV disease progression among HIVinfected individuals of China. J Acquir Immune Defic Syndr (2010) 53(Suppl 1):S4-9. doi:10.1097/ QAI.0b013e3181c7d349

187. Gandhi SK, Siliciano JD, Bailey JR, Siliciano RF, Blankson JN. Role of APOBEC3G/F-mediated hypermutation in the control of human immunodeficiency virus type 1 in elite suppressors. J Virol (2008) 82:3125-30. doi:10.1128/ JVI.01533-07

188. Land AM, Ball TB, Luo M, Pilon R, Sandstrom P, Embree JE, et al. Human immunodeficiency virus (HIV) type 1 proviral hypermutation correlates with CD4 count in HIV-infected women from Kenya. J Virol (2008) 82:8172-82. doi:10. 1128/JVI.01115-08

189. Piantadosi A, Humes D, Chohan B, McClelland RS, Overbaugh J. Analysis of the percentage of human immunodeficiency virus type 1 sequences that are hypermutated and markers of disease progression in a longitudinal cohort, including one individual with a partially defective Vif. $J$ Virol (2009) 83:7805-14. doi:10. 1128/JVI.00280-09

190. Buzon MJ, Seiss K, Weiss R, Brass AL, Rosenberg ES, Pereyra F, et al. Inhibition of HIV-1 integration in ex vivo-infected CD4 T cells from elite controllers. $J$ Virol (2011) 85:9646-50. doi:10.1128/ JVI.05327-11

191. Graf EH, Mexas AM, Yu JJ, Shaheen F, Liszewski MK, Di MM, et al. Elite suppressors harbor low levels of integrated HIV DNA and high levels of 2-LTR circular HIV DNA compared to HIV+ patients on and off HAART. PLoS Pathog (2011) 7:e1001300. doi:10.1371/ journal.ppat.1001300

192. Kourteva Y, De PM, Allos T, McMunn C, D’Aquila RT. APOBEC3G expression and hypermutation are inversely associated with human immunodeficiency virus type 1 (HIV-1) burden 
in vivo. Virology (2012) 430:1-9. doi:10.1016/j.virol.2012.03.018

193. Pido-Lopez J, Whittall T, Wang Y, Bergmeier LA, Babaahmady K, Singh M, et al. Stimulation of cell surface CCR5 and CD40 molecules by their ligands or by HSP70 up-regulates APOBEC3G expression in CD4(+) T cells and dendritic cells. J Immunol (2007) 178:1671-9.

194. Lafferty MK, Sun L, DeMasi L, Lu W, Garzino-Demo A. CCR6 ligands inhibit HIV by inducing APOBEC3G. Blood (2010) 115:1564-71. doi:10.1182/blood2009-06-226423

195. Ali A, Wang J, Nathans RS, Cao H, Sharova N, Stevenson M, et al. Synthesis and structure-activity relationship studies of HIV-1 virion infectivity factor (Vif) inhibitors that block viral replication. ChemMedChem (2012) 7:1217-29. doi:10.1002/cmdc.201200079

196. Nathans R, Cao H, Sharova N, Ali A, Sharkey M, Stranska R, et al. Small-molecule inhibition of HIV-1 Vif. Nat Biotechnol (2008) 26:1187-92. doi:10.1038/nbt.1496

197. Goncalves J, Silva F, Freitas-Vieira A, Santa-Marta M, Malho R, Yang $\mathrm{X}$, et al. Functional neutralization of HIV-1 Vif protein by intracellular immunization inhibits reverse transcription and viral replication. J Biol Chem (2002) 277: 32036-45. doi:10.1074/jbc. M201906200

198. Cen S, Peng ZG, Li XY, Li ZR, Ma J, Wang YM, et al. Small molecular compounds inhibit HIV1 replication through specifically stabilizing APOBEC3G. J Biol Chem (2010) 285:16546-52. doi: 10.1074/jbc.M109.085308

199. Ao Z, Yu Z, Wang L, Zheng Y, Yao X. Vpr14-88-Apobec3G fusion protein is efficiently incorporated into Vif-positive HIV-1 particles and inhibits viral infection. PLoS ONE (2008) 3:e1995. doi:10.1371/ journal.pone.0001995

200. Green LA, Liu Y, He JJ. Inhibition of HIV-1 infection and replication by enhancing viral incorporation of innate anti-HIV-1 protein A3G: a non-pathogenic Nef mutant-based anti-HIV strategy. $J$ Biol Chem (2009) 284:13363-72. doi:10.1074/jbc.M806631200

201. Porcellini S, Gubinelli F, Alberici L, Piovani BM, Rizzardi GP, Bovolenta C. Chim3 confers survival advantage to $\mathrm{CD} 4+\mathrm{T}$ cells upon HIV-1 infection by preventing HIV-1 DNA integration and HIV-1-induced G2 cell-cycle delay.
Blood (2010) 115:4021-9. doi:10. 1182/blood-2009-09-243030

202. Reymond A, Meroni G, Fantozzi A, Merla G, Cairo S, Luzi L, et al. The tripartite motif family identifies cell compartments. $E M B O$ $J$ (2001) 20:2140-51. doi:10.1093/ emboj/20.9.2140

203. Meroni G, Diez-Roux G. TRIM/RBCC, a novel class of 'single protein RING finger' E3 ubiquitin ligases. Bioessays (2005) 27:1147-57. doi:10.1002/bies.20304

204. Ozato K, Shin DM, Chang TH, Morse HC III. TRIM family proteins and their emerging roles in innate immunity. Nat Rev Immunol (2008) 8:849-60. doi:10. $1038 /$ nri2413

205. Nisole S, Stoye JP, Saib A. TRIM family proteins: retroviral restriction and antiviral defence. Nat Rev Microbiol (2005) 3:799-808. doi: 10.1038/nrmicro1248

206. Sayah DM, Sokolskaja E, Berthoux L, Luban J. Cyclophilin A retrotransposition into TRIM5 explains owl monkey resistance to HIV-1. Nature (2004) 430:569-73. doi:10. 1038/nature02777

207. Stremlau M, Owens CM, Perron MJ, Kiessling M, Autissier P, Sodroski J. The cytoplasmic body component TRIM5alpha restricts HIV-1 infection in old world monkeys. Nature (2004) 427:848-53. doi:10.1038/nature02343

208. Perron MJ, Stremlau M, Song B, Ulm W, Mulligan RC, Sodroski J. TRIM5alpha mediates the postentry block to $\mathrm{N}$-tropic murine leukemia viruses in human cells. Proc Natl Acad Sci U S A (2004) 101:11827-32. doi:10.1073/pnas. 0403364101

209. Yap MW, Nisole S, Lynch C, Stoye JP. Trim5alpha protein restricts both HIV-1 and murine leukemia virus. Proc Natl Acad Sci U S A (2004) 101:10786-91. doi:10. 1073/pnas.0402876101

210. Nisole S, Lynch C, Stoye JP, Yap MW. A Trim5-cyclophilin A fusion protein found in owl monkey kidney cells can restrict HIV1. Proc Natl Acad Sci U S A (2004) 101:13324-8. doi:10.1073/ pnas.0404640101

211. Perez-Caballero D, Hatziioannou $\mathrm{T}$, Yang A, Cowan S, Bieniasz PD. Human tripartite motif 5alpha domains responsible for retrovirus restriction activity and specificity. J Virol (2005) 79:8969-78. doi:10. 1128/JVI.79.14.8969-8978.2005

212. Stremlau M, Perron M, Welikala S, Sodroski J. Species-specific variation in the B30.2(SPRY) domain of TRIM5alpha determines the potency of human immunodeficiency virus restriction. J Virol (2005) 79:3139-45. doi:10.1128/JVI.79.5.3139-3145. 2005

213. Diaz-Griffero F, Qin XR, Hayashi F, Kigawa T, Finzi A, Sarnak Z, et al. A B-box 2 surface patch important for TRIM5alpha selfassociation, capsid binding avidity, and retrovirus restriction. $J$ Virol (2009) 83:10737-51. doi:10.1128/ JVI.01307-09

214. Kar AK, Diaz-Griffero F, Li Y, Li X, Sodroski J. Biochemical and biophysical characterization of a chimeric TRIM21-TRIM5alpha protein. J Virol (2008) 82:11669-81. doi:10.1128/JVI.01559-08

215. Langelier CR, Sandrin V, Eckert DM, Christensen DE, Chandrasekaran V, Alam SL, et al. Biochemical characterization of a recombinant TRIM5alpha protein that restricts human immunodeficiency virus type 1 replication. $J$ Virol (2008) 82:11682-94. doi:10. 1128/JVI.01562-08

216. Ganser-Pornillos BK, Chandrasekaran V, Pornillos O, Sodroski JG, Sundquist WI, Yeager M Hexagonal assembly of a restricting TRIM5alpha protein. Proc Natl Acad Sci U S A (2011) 108:534-9. doi:10.1073/pnas.1013426108

217. Javanbakht H, Yuan W, Yeung DF, Song B, Diaz-Griffero F, Li Y, et al. Characterization of TRIM5alpha trimerization and its contribution to human immunodeficiency virus capsid binding. Virology (2006) 353:234-46. doi:10.1016/j. virol.2006.05.017

218. Li X, Sodroski J. The TRIM5alpha B-box 2 domain promotes cooperative binding to the retroviral capsid by mediating higherorder self-association. J Virol (2008) 82:11495-502. doi:10.1128/ JVI.01548-08

219. Mische CC, Javanbakht H, Song B, Diaz-Griffero F, Stremlau M, Strack B, et al. Retroviral restriction factor TRIM5alpha is a trimer. JVirol (2005) 79:14446-50. doi:10.1128/JVI.79.22.1444614450.2005

220. Pertel T, Hausmann S, Morger D, Zuger S, Guerra J, Lascano J, et al. TRIM5 is an innate immune sensor for the retrovirus capsid lattice. Nature (2011) 472:361-5. doi:10. 1038/nature09976

221. Javanbakht H, Diaz-Griffero F, Stremlau M, Si Z, Sodroski J. The contribution of RING and B-box 2 domains to retroviral restriction mediated by monkey TRIM5alpha. J Biol Chem (2005) 280:26933-40. doi:10.1074/jbc.M502145200

222. Stremlau M, Perron M, Lee M, Li $\mathrm{Y}$, Song B, Javanbakht $\mathrm{H}$, et al. Specific recognition and accelerated uncoating of retroviral capsids by the TRIM5alpha restriction factor. Proc Natl Acad Sci U S A (2006) 103:5514-9. doi:10.1073/ pnas.0509996103

223. Wu X, Anderson JL, Campbell EM, Joseph AM, Hope TJ. Proteasome inhibitors uncouple rhesus TRIM5alpha restriction of HIV1 reverse transcription and infection. Proc Natl Acad Sci U S A (2006) 103:7465-70. doi:10.1073/ pnas. 0510483103

224. Goldschmidt V, Bleiber G, May M, Martinez R, Ortiz M, Telenti A. Role of common human TRIM5alpha variants in HIV1 disease progression. Retrovirology (2006) 3:54. doi:10.1186/ 1742-4690-3-S1-S54

225. Sawyer SL, Wu LI, Akey JM, Emerman M, Malik HS. High-frequency persistence of an impaired allele of the retroviral defense gene TRIM5alpha in humans. Curr Biol (2006) 16:95-100. doi:10.1016/j. cub.2005.11.045

226. Javanbakht H, An P, Gold B, Petersen DC, O'Huigin C, Nelson GW, et al. Effects of human TRIM5alpha polymorphisms on antiretroviral function and susceptibility to human immunodeficiency virus infection. Virology (2006) 354:15-27. doi:10.1016/j.virol.2006.06.031

227. Nakayama EE, Carpentier W, Costagliola D, Shioda T, Iwamoto A, Debre P, et al. Wild type and $\mathrm{H} 43 \mathrm{Y}$ variant of human TRIM5alpha show similar anti-human immunodeficiency virus type 1 activity both in vivo and in vitro. Immunogenetics (2007) 59:511-5. doi:10.1007/s00251-007-0217-7

228. Liu FL, Qiu YQ, Li H, Kuang YQ, Tang X, Cao G, et al. An HIV-1 resistance polymorphism in TRIM5alpha gene among Chinese intravenous drug users. $J$ Acquir Immune Defic Syndr (2011) 56:306-11. doi:10.1097/ QAI.0b013e318205a59b

229. Price H, Lacap P, Tuff J, Wachihi C, Kimani J, Ball TB, et al. A TRIM5alpha exon 2 polymorphism is associated with protection from HIV-1 infection in the Pumwani sex worker cohort. AIDS 
(2010) 24:1813-21. doi:10.1097/ QAD.0b013e32833b5256

230. van Manen D, Rits MA, Beugeling C, van Dort K, Schuitemaker H, Kootstra NA. The effect of Trim5 polymorphisms on the clinical course of HIV-1 infection. PLoS Pathog (2008) 4:e18. doi:10.1371/journal.ppat. 0040018

231. Anderson J, Akkina R. TRIM5alpharh expression restricts HIV-1 infection in lentiviral vector-transduced CD34+-cell-derived macrophages. Mol Ther (2005) 12:687-96. doi:10.1016/j.ymthe.2005.07.291

232. Anderson J, Akkina R. Human immunodeficiency virus type 1 restriction by human-rhesus chimeric tripartite motif 5alpha (TRIM 5alpha) in CD34(+) cell-derived macrophages in vitro and in $\mathrm{T}$ cells in vivo in severe combined immunodeficient (SCID-hu) mice transplanted with human fetal tissue. Hum Gene Ther (2008) 19:217-28. doi:10.1089/hum.2007.108

233. Anderson JS, Javien J, Nolta JA, Bauer G. Preintegration HIV1 inhibition by a combination lentiviral vector containing a chimeric TRIM5 alpha protein, a CCR5 shRNA, and a TAR decoy. Mol Ther (2009) 17:2103-14. doi: 10.1038/mt.2009.187

234. Walker JE, Chen RX, McGee J, Nacey C, Pollard RB, Abedi M, et al. Generation of an HIV-1-resistant immune system with $\mathrm{CD} 34(+)$ hematopoietic stem cells transduced with a triple-combination anti-HIV lentiviral vector. $J$ Virol (2012) 86:5719-29. doi:10.1128/ JVI.06300-11

235. Neagu MR, Ziegler P, Pertel T, Strambio-De-Castillia C, Grutter C, Martinetti G, et al. Potent inhibition of HIV-1 by TRIM5cyclophilin fusion proteins engineered from human components. $J$ Clin Invest (2009) 119:3035-47. doi:10.1172/JCI39354

236. Pham QT, Bouchard A, Grutter MG, Berthoux L. Generation of human TRIM5alpha mutants with high HIV-1 restriction activity. Gene Ther (2010) 17:859-71. doi: 10.1038/gt.2010.40

237. Andrew AJ, Kao S, Strebel K. C-terminal hydrophobic region in human bone marrow stromal cell antigen 2 (BST-2)/tetherin protein functions as second transmembrane motif. $J$ Biol Chem (2011) 286:39967-81. doi:10.1074/jbc.M111.287011
238. Kupzig S, Korolchuk V, Rollason R, Sugden A, Wilde A, Banting G. Bst-2/HM1.24 is a raftassociated apical membrane protein with an unusual topology. Traffic (2003) 4:694-709. doi:10. 1034/j.1600-0854.2003.00129.x

239. Habermann A, Krijnse-Locker J, Oberwinkler H, Eckhardt $\mathrm{M}$, Homann S, Andrew A, et al. CD317/tetherin is enriched in the HIV-1 envelope and downregulated from the plasma membrane upon virus infection. J Virol (2010) 84:4646-58. doi:10.1128/ JVI.02421-09

240. Masuyama N, Kuronita T, Tanaka $\mathrm{R}$, Muto T, Hirota $\mathrm{Y}$, Takigawa A, et al. HM1.24 is internalized from lipid rafts by clathrinmediated endocytosis through interaction with alpha-adaptin. $J$ Biol Chem (2009) 284:15927-41. doi:10.1074/jbc.M109.005124

241. Rollason R, Korolchuk V, Hamilton C, Schu P, Banting G. Clathrinmediated endocytosis of a lipidraft-associated protein is mediated through a dual tyrosine motif. $J$ Cell Sci (2007) 120:3850-8. doi:10. $1242 /$ jcs. 003343

242. Ohtomo T, Sugamata Y, Ozaki Y, Ono K, Yoshimura Y, Kawai S, et al. Molecular cloning and characterization of a surface antigen preferentially overexpressed on multiple myeloma cells. Biochem Biophys Res Commun (1999) 258:583-91. doi:10.1006/bbrc.1999.0683

243. Schubert HL, Zhai Q, Sandrin V, Eckert DM, Garcia-Maya M, Saul L, et al. Structural and functional studies on the extracellular domain of BST2/tetherin in reduced and oxidized conformations. Proc Natl Acad Sci U S A (2010) 107:17951-6. doi:10.1073/ pnas. 1008206107

244. Yang H, Wang J, Jia X, McNatt MW, Zang T, Pan B, et al. Structural insight into the mechanisms of enveloped virus tethering by tetherin. Proc Natl Acad Sci U S A (2010) 107:18428-32. doi:10. 1073/pnas.1011485107

245. Hinz A, Miguet N, Natrajan G, Usami Y, Yamanaka H, Renesto P, et al. Structural basis of HIV-1 tethering to membranes by the BST2/tetherin ectodomain. Cell Host Microbe (2010) 7:314-23. doi:10. 1016/j.chom.2010.03.005

246. Ishikawa J, Kaisho T, Tomizawa $\mathrm{H}$, Lee BO, Kobune $\mathrm{Y}$, Inazawa J, et al. Molecular cloning and chromosomal mapping of a bone marrow stromal cell surface gene, BST2, that may be involved in pre-B-cell growth. Genomics (1995) 26:527-34. doi:10.1016/ 0888-7543(95)80171-H

247. Blasius AL, Giurisato E, Cella M, Schreiber RD, Shaw AS, Colonna $\mathrm{M}$. Bone marrow stromal cell antigen 2 is a specific marker of type I IFN-producing cells in the naïve mouse, but a promiscuous cell surface antigen following IFN stimulation. JImmunol (2006) 177:3260-5.

248. Miyagi E, Andrew AJ, Kao S, Strebel K. Vpu enhances HIV1 virus release in the absence of Bst-2 cell surface downmodulation and intracellular depletion. Proc Natl Acad Sci U S A (2009) 106:2868-73. doi:10.1073/pnas.0813223106

249. Vidal-Laliena M, Romero X, March S, Requena V, Petriz J, Engel P. Characterization of antibodies submitted to the B cell section of the 8th human leukocyte differentiation antigens workshop by flow cytometry and immunohistochemistry. Cell Immunol (2005) 236:6-16. doi:10.1016/j.cellimm. 2005.08.002

250. Cao W, Bover L, Cho M, Wen X, Hanabuchi S, Bao M, et al. Regulation of TLR7/9 responses in plasmacytoid dendritic cells by BST2 and ILT7 receptor interaction. $J$ Exp Med (2009) 206:1603-14. doi: 10.1084/jem.20090547

251. Neil SJ, Zang T, Bieniasz PD. Tetherin inhibits retrovirus release and is antagonized by HIV-1 $\mathrm{Vpu}$. Nature (2008) 451:425-30. doi:10. 1038/nature06553

252. Van Damme N, Goff D, Katsura C, Jorgenson RL, Mitchell R, Johnson MC, et al. The interferoninduced protein BST-2 restricts HIV-1 release and is downregulated from the cell surface by the viral Vpu protein. Cell Host Microbe (2008) 3:245-52. doi:10. 1016/j.chom.2008.03.001

253. Swiecki M, Wang Y, Gilfillan S, Lenschow DJ, Colonna M. Cutting edge: paradoxical roles of BST2/tetherin in promoting type I IFN response and viral infection. $J$ Immunol (2012) 188:2488-92. doi: 10.4049/jimmunol.1103145

254. Miyakawa K, Ryo A, Murakami T, Ohba K, Yamaoka S, Fukuda $\mathrm{M}$, et al. BCA2/Rabring7 promotes tetherin-dependent HIV-1 restriction. PLoS Pathog (2009) 5:e1000700. doi:10.1371/journal. ppat. 1000700

255. Casartelli N, Sourisseau M, Feldmann J, Guivel-Benhassine F, Mallet A, Marcelin AG, et al.
Tetherin restricts productive HIV1 cell-to-cell transmission. PLoS Pathog (2010) 6:e1000955. doi:10. 1371/journal.ppat.1000955

256. Jolly C, Booth NJ, Neil SJ. Cell-cell spread of human immunodeficiency virus type 1 overcomes tetherin/BST-2mediated restriction in $\mathrm{T}$ cells. $J$ Virol (2010) 84:12185-99. doi:10.1128/JVI.01447-10

257. Kuhl BD, Sloan RD, Donahue DA, Bar-Magen T, Liang C, Wainberg MA. Tetherin restricts direct cellto-cell infection of HIV-1. Retrovirology (2010) 7:115. doi:10.1186/ 1742-4690-7-115

258. Liberatore RA, Bieniasz PD. Tetherin is a key effector of the antiretroviral activity of type I interferon in vitro and in vivo. Proc Natl Acad Sci U S A (2011) 108:18097-101. doi:10.1073/pnas. 1113694108

259. Fitzpatrick K, Skasko M, Deerinck TJ, Crum J, Ellisman MH, Guatelli J. Direct restriction of virus release and incorporation of the interferon-induced protein BST-2 into HIV-1 particles. PLoS Pathog (2010) 6:e1000701. doi:10. 1371/journal.ppat.1000701

260. Hammonds J, Wang JJ, Yi H, Spearman P. Immunoelectron microscopic evidence for Tetherin/BST2 as the physical bridge between HIV-1 virions and the plasma membrane. PLoS Pathog (2010) 6:e1000749. doi:10.1371/journal. ppat.1000749

261. Perez-Caballero D, Zang T, Ebrahimi A, McNatt MW, Gregory $\mathrm{DA}$, Johnson $\mathrm{MC}$, et al. Tetherin inhibits HIV-1 release by directly tethering virions to cells. Cell (2009) 139:499-511. doi:10.1016/j.cell.2009.08.039

262. Kuhl BD, Cheng V, Wainberg MA, Liang C. Tetherin and its viral antagonists. J Neuroimmune Pharmacol (2011) 6:188-201. doi:10. 1007/s11481-010-9256-1

263. Douglas JL, Viswanathan K, McCarroll MN, Gustin JK, Fruh K, Moses AV. Vpu directs the degradation of the human immunodeficiency virus restriction factor BST-2/Tetherin via a \{beta\}TrCP-dependent mechanism. J Virol (2009) 83:7931-47. doi:10.1128/JVI.00242-09

264. Dube M, Roy BB, Guiot-Guillain P, Binette J, Mercier J, Chiasson A, et al. Antagonism of tetherin restriction of HIV-1 release by Vpu involves binding and sequestration of the restriction factor in a perinuclear compartment. PLoS 
Pathog (2010) 6:e1000856. doi:10. 1371/journal.ppat.1000856

265. Goffinet C, Allespach I, Homann S, Tervo HM, Habermann A, Rupp D, et al. HIV-1 antagonism of CD317 is species specific and involves Vpu-mediated proteasomal degradation of the restriction factor. Cell Host Microbe (2009) 5:285-97. doi: 10.1016/j.chom.2009.01.009

266. Iwabu Y, Fujita H, Kinomoto M, Kaneko K, Ishizaka Y, Tanaka $\mathrm{Y}$, et al. HIV-1 accessory protein $\mathrm{Vpu}$ internalizes cellsurface BST-2/tetherin through transmembrane interactions leading to lysosomes. $J$ Biol Chem (2009) 284:35060-72. doi:10.1074/jbc.M109.058305

267. Mitchell RS, Katsura C, Skasko MA, Fitzpatrick K, Lau D, Ruiz A, et al. Vpu antagonizes BST2-mediated restriction of HIV-1 release via beta- $\operatorname{TrCP}$ and endolysosomal trafficking. PLoS Pathog (2009) 5:e1000450. doi:10.1371/ journal.ppat.1000450

268. Skasko M, Wang Y, Tian Y, Tokarev A, Munguia J, Ruiz A, et al. HIV$1 \mathrm{Vpu}$ protein antagonizes innate restriction factor BST-2 via lipidembedded helix-helix interactions. J Biol Chem (2012) 287:58-67. doi: 10.1074/jbc.M111.296772

269. Hauser H, Lopez LA, Yang SJ, Oldenburg JE, Exline CM, Guatelli JC, et al. HIV-1 Vpu and HIV2 Env counteract BST-2/tetherin by sequestration in a perinuclear compartment. Retrovirology (2010) 7:51. doi:10.1186/17424690-7-51

270. Le Tortorec A, Neil SJ. Antagonism to and intracellular sequestration of human tetherin by the human immunodeficiency virus type 2 envelope glycoprotein. $J$ Virol (2009) 83:11966-78. doi:10. 1128/JVI.01515-09

271. Mous K, Jennes W, Camara M, Seydi M, Daneau G, Mboup $\mathrm{S}$, et al. Expression analysis of LEDGF/p75, APOBEC3G, TRIM5alpha, and tetherin in a Senegalese cohort of HIV-1exposed seronegative individuals. PLoS ONE (2012) 7:e33934. doi: 10.1371/journal.pone.0033934

272. Homann S, Smith D, Little S, Richman D, Guatelli J. Upregulation of BST-2/Tetherin by HIV infection in vivo. JVirol (2011) 85:10659-68. doi:10.1128/JVI.05524-11

273. Pillai SK, Abdel-Mohsen M, Guatelli J, Skasko M, Monto A, Fujimoto K, et al. Role of retroviral restriction factors in the interferon-alphamediated suppression of HIV-1 in vivo. Proc Natl Acad Sci U S A (2012) 109:3035-40. doi:10.1073/pnas.1111573109

274. Herbeuval JP, Shearer GM. HIV1 immunopathogenesis: how good interferon turns bad. Clin Immunol (2007) 123:121-8. doi:10.1016/j. clim.2006.09.016

275. Lv M, Wang J, Zhu Y, Wang $\mathrm{X}$, Zuo T, Liu D, et al. Overexpression of inactive tetherin delGPI mutant inhibits HIV1 Vpu-mediated antagonism of endogenous tetherin. FEBS Lett (2013) 587:37-43. doi:10.1016/j. febslet.2012.11.022

276. Aviv T, Lin Z, Lau S, Rendl LM, Sicheri F, Smibert CA. The RNA-binding SAM domain of Smaug defines a new family of post-transcriptional regulators. Nat Struct Biol (2003) 10:614-21. doi:10.1038/nsb956

277. Oberstrass FC, Lee A, Stefl R, Janis M, Chanfreau G, Allain FH. Shape-specific recognition in the structure of the Vtslp SAM domain with RNA. Nat Struct Mol Biol (2006) 13:160-7. doi:10.1038/ nsmb1038

278. Brandariz-Nunez A, Valle-Casuso JC, White TE, Laguette N, Benkirane $\mathrm{M}$, Brojatsch J, et al. Role of SAMHD1 nuclear localization in restriction of HIV-1 and SIVmac. Retrovirology (2012) 9:49. doi:10. 1186/1742-4690-9-49

279. Hofmann H, Logue EC, Bloch N, Daddacha W, Polsky SB, Schultz $\mathrm{ML}$, et al. The Vpx lentiviral accessory protein targets SAMHD1 for degradation in the nucleus. J Virol (2012) 86:12552-60. doi:10.1128/ JVI.01657-12

280. White TE, Brandariz-Nunez A, Carlos Valle-Casuso J, Amie S, Nguyen L, Kim B, et al. Contribution of SAM and HD domains to retroviral restriction mediated by human SAMHD1. Virology (2013) 436:81-90. doi:10.1016/j. virol.2012.10.029

281. Baldauf HM, Pan X, Erikson E, Schmidt S, Daddacha W, Burggraf $\mathrm{M}$, et al. SAMHD1 restricts HIV1 infection in resting $\mathrm{CD} 4(+) \mathrm{T}$ cells. Nat Med (2012) 18:1682-7. doi:10.1038/nm.2964

282. Wu L. SAMHD1: a new contributor to HIV-1 restriction in resting CD4+ T-cells. Retrovirology (2012) 9:88. doi:10.1186/17424690-9-88

283. Aravind L, Koonin EV. The HD domain defines a new superfamily of metal-dependent phosphohydrolases. Trends Biochem Sci (1998) 23:469-72. doi:10.1016/ S0968-0004(98)01293-6
284. Goldstone DC, Ennis-Adeniran $\mathrm{V}$, Hedden JJ, Groom HC, Rice GI, Christodoulou E, et al. HIV-1 restriction factor SAMHD1 is a deoxynucleoside triphosphate triphosphohydrolase. Nature (2011) 480:379-82. doi:10.1038/nature10623

285. Berger A, Sommer AF, Zwarg J, Hamdorf M, Welzel K, Esly N, et al. SAMHD1-deficient CD14+ cells from individuals with AicardiGoutieres syndrome are highly susceptible to HIV-1 infection. PLoS Pathog (2011) 7:e1002425. doi:10.1371/journal.ppat.1002425

286. St GC, de SS, Amie SM, Coleman $\mathrm{CM}$, Hoy H, Hollenbaugh JA, et al. SAMHD1 restricts HIV-1 infection in dendritic cells (DCs) by dNTP depletion, but its expression in DCs and primary CD4+ T-lymphocytes cannot be upregulated by interferons. Retrovirology (2012) 9:105. doi:10.1186/17424690-9-105

287. Powell RD, Holland PJ, Hollis T, Perrino FW. Aicardi-Goutieres syndrome gene and HIV-1 restriction factor SAMHD1 is a dGTP-regulated deoxynucleotide triphosphohydrolase. J Biol Chem (2011) 286:43596-600. doi:10.1074/jbc.C111.317628

288. Descours B, Cribier A, ChableBessia C, Ayinde D, Rice G, Crow $\mathrm{Y}$, et al. SAMHD1 restricts HIV1 reverse transcription in quiescent CD4(+) T-cells. Retrovirology (2012) 9:87. doi:10.1186/ 1742-4690-9-87

289. Hrecka K, Hao C, Gierszewska M, Swanson SK, Kesik-Brodacka M, Srivastava S, et al. Vpx relieves inhibition of HIV-1 infection of macrophages mediated by the SAMHD1 protein. Nature (2011) 474:658-61. doi:10.1038/ nature 10195

290. Laguette N, Sobhian B, Casartelli $N$, Ringeard $M$, Chable-Bessia C, Segeral E, et al. SAMHD1 is the dendritic- and myeloidcell-specific HIV-1 restriction factor counteracted by Vpx. Nature (2011) 474:654-7. doi:10.1038/ nature 10117

291. Kim B, Nguyen LA, Daddacha W, Hollenbaugh JA. Tight interplay among SAMHD1 protein level, cellular dNTP levels, and HIV1 proviral DNA synthesis kinetics in human primary monocytederived macrophages. J Biol Chem (2012) 287:21570-4. doi:10.1074/ jbc.C112.374843

292. Lahouassa H, Daddacha W, Hofmann H, Ayinde D, Logue EC, Dragin L, et al. SAMHD1 restricts the replication of human immunodeficiency virus type 1 by depleting the intracellular pool of deoxynucleoside triphosphates. Nat Immunol (2012) 13:223-8. doi:10.1038/ni.2236

293. Manel N, Hogstad B, Wang Y, Levy DE, Unutmaz D, Littman DR. A cryptic sensor for HIV-1 activates antiviral innate immunity in dendritic cells. Nature (2010) 467:214-7. doi:10.1038/ nature09337

294. Welbourn S, Miyagi E, White TE, Diaz-Griffero F, Strebel K. Identification and characterization of naturally occurring splice variants of SAMHD1. Retrovirology (2012) 9:86. doi:10.1186/1742-4690-9-86

295. Rice GI, Bond J, Asipu A, Brunette RL, Manfield IW, Carr IM, et al. Mutations involved in Aicardi-Goutieres syndrome implicate SAMHD1 as regulator of the innate immune response. Nat Genet (2009) 41:829-32. doi:10. 1038/ng.373

296. Coon S, Wang D, Wu L. Polymorphisms of the SAMHD1 gene are not associated with the infection and natural control of HIV type 1 in Europeans and AfricanAmericans. AIDS Res Hum Retroviruses (2012) 28:1565-73. doi:10. 1089/AID.2012.0039

Conflict of Interest Statement: The authors declare that the research was conducted in the absence of any commercial or financial relationships that could be construed as a potential conflict of interest.

Received: 20 March 2013; paper pending published: 01 May 2013; accepted: 06 October 2013; published online: 24 October 2013.

Citation: Santa-Marta M, de Brito PM, Godinho-Santos $A$ and Goncalves (2013) Host factors and HIV-1 replication: clinical evidence and potential therapeutic approaches. Front. Immunol. 4:343. doi: 10.3389/fimmu.2013.00343

This article was submitted to HIV and AIDS, a section of the journal Frontiers in Immunology.

Copyright $\odot 2013$ Santa-Marta, de Brito, Godinho-Santos and Goncalves. This is an open-access article distributed under the terms of the Creative Commons Attribution License (CC BY). The use, distribution or reproduction in other forums is permitted, provided the original author(s) or licensor are credited and that the original publication in this journal is cited, in accordance with accepted academic practice. No use, distribution or reproduction is permitted which does not comply with these terms. 